\title{
Spectroscopic and Quantum Computational Investigation of 3-Cyano chromone
}

\author{
Parthasarathi. $A^{1}$, Jayasheela. $K^{2}$, Prabhu. $T^{3}$, Karthikeyan. $S^{4}$, Periandy. $S^{5}$
}

\begin{abstract}
In the present study, Molecular docking, Reduced density gradient analysis, Electron Localization function (ELF) analysis were carried out. FT-IR, FT-Raman, NMR and UV spectra of 3-cynochromone are recorded at the appropriate ranges. The fundamental vibrational frequencies are tabulated and assigned. Quantum computations were carried out using B3LYP method with cc-pVDZ basis sets and the corresponding results are compared with the experimental values. The change in the chemical environment of the compound is studied using NMR chemical shift values. The ${ }^{13} \mathrm{C}$ NMR and ${ }^{1} \mathrm{H}$ NMR chemical shifts were calculated using the gauge-independent atomic orbital (GIAO) method, with the B3LYP functional and the cc-pVDZ basis set and their spectra is compared with the experimental spectra. A study on the electronic and optical properties; absorption wavelengths, excitation energy, density of state, dipole moment and frontier molecular orbital energies were also performed using DFT methods and UV-Vis spectrum. The calculated HOMO and LUMO are displayed with energy gap, which show the occurrence of charge transfer within the molecule. NLO properties are related to polarizability, dipole moment and hyperpolarizability, and thermodynamically parameters are also discussed.
\end{abstract}

Keywords - Molecular docking, RDG, ELF (2D \&3D), NMR, vibrational and cc-pVDZ basis set.

\section{INTRODUCTION}

Cyano derivatives are ubiquitous in nature. The cyano group is considered one of the most abundant functional groups on earth, second only to the amino group [1].

It is also present in significant amounts in dense interstellar clouds [2] and comet. Roughly 2000 plants produce cyano compounds, some of them being cyanogenic glycosides [3]. In organic synthesis, cyano groups play a very special role. They are not only

Parthasarathi. A, Department of physics, A.V.C. College, Mayiladuthurai, Tamil nadu-609 305.

Jayasheela. K, Department of physics, Kanchi mamunivar center for post graduate studies, lawspet, Pondicherry-605008.

Parbhu. T, Department of physics, A.V.C. College, Mayiladuthurai, Tamil nadu-609 305.

Karthikeyan. S, Department of physics, Kanchi mamunivar center for post graduate studies, lawspet, Pondicherry-605008.

Periandy. S, Department of physics, Kanchi mamunivar center for post graduate studies, lawspet, Pondicherry-605008. active groups in pesticides, medicines, and dyes, but also important radicals of aldehydes, amines, amidines, thiophenes, triazoles, tetrazoles, and carboxylic acids [4]. Moreover, cyano substitution plays a specific role in molecular modification techniques because the $\mathrm{CN}$ group can affect p-conjugation, leading to significant changes in the strength of adjacent bonds [5]. As the cyano group has specific electric properties and structural features, it is always used in the synthesis of new compounds. As a small substituent with strong electron-withdrawing properties, the $\mathrm{CN}$ group enables the establishment of intermolecular contact between molecules in the solid state [6].The possible crucial role of $\mathrm{HCN}$ and polycyano compounds in prebiotic synthesis and chemical evolution, for example, has interested researchers for decades. The universality of the $\mathrm{CN}$ group is reflected in polycyano compounds that act as dyes or organic metals. Polycyano anions are important ingredients of materials exhibiting very strong electrical conductivity. It is quite possible that polycyano derivatives of organic molecules will play a significant role in superacid-superbase chemistry in the future [7].Chromone is a derivative of benzopyran with a substituted keto group on the pyrone ring. Chromone is oxygen-containing heterocyclic compounds. Chromone are the subject of increasing interest due to a wide use of these heterocyclic compounds as structural building blocks for the design of various promising pharmacological agents and components for super-high capacity optical archive storage systems. Although the chromone core does not contain a nitrogen atom, chromone natural products are classified as alkaloids because nitrogenous moieties are usually attached to them [8]. In the FDA Orange Book, the chromone core is one of the top 100 most used ring systems for small molecule drugs listed [9].

Chromone exhibit important pharmacological activities, such as anti-inflammatory and anticancer due to their well-recognized antioxidant properties [10]. These compounds show the variety of pharmacological activities and the change in their structure offer a high degree of diversity that has been found useful for the search for novel therapeutic agents. It is common and integral constituent of a variety of medicinal agents [11]. Chromone-based drugs exhibit anticancer, anti-HIV, antioxidant, anti-inflammatory, analgesic, antimicrobial, antimalarial, anti-diabetic, anticonvulsant, antiplatelet, gastroprotective, antihistaminic, antihypertensive, and insecticidal activity [9-11]. Several other significant studies have also been reported along the years on the medicinal application of simple Chromone, such as 
antioxidants, antidiabetics and cardiovascular agents, diuretics, hypoglycemic, hypolipidemic, antiarrhythmic and hypotensive agents. Due to the profound application as potential therapeutic agent in conjunction with synthetic accessibility and structural diversity, chromone group of compounds are often regarded as privileged scaffold in drug discovery and numerous reviews are available to justify a series of versatile synthetic methods involving them.

This present study aims to analyze both experimentally and theoretically the 3 cyano chromone compound by recording FTIR, FT-Raman, NMR and $\mathrm{UV}-\mathrm{V}$ is spectra and doing quantum chemical computations using DFT methods on the molecule. In this work the structural, conformational, and vibrational analysis of the compound are carried out by using B3LYP functional. The electron density (ED) in various bonding and anti-bonding orbital and stabilisation energies are predicted by Natural Bond Orbital (NBO) analysis. The UV spectroscopic studies along with HOMO-LUMO analysis have been used to explain the charge transfer within the molecule. In addition Docking analysis were also carried out using Auto-dock software to understand the biological activity of the compound.

\section{METHODS}

\section{A. Experimental details}

The 3-cyanochromone compound is purchased from Tokyo Chemical Industry (TCI) Co., Ltd., Tokyo, Japan. Chemical which is of spectroscopic grade and hence used for recording the spectra as such without any further purification. The NMR ${ }^{13} \mathrm{C} \&{ }^{1} \mathrm{H}$ spectra were recorded in the range of 20-200\& 1-10ppmrespectively, with the scanning interval of 20 ppm in $\mathrm{CdCl}_{3}$ ) solvent phase. The FT-IR spectrum was recorded by $\mathrm{KBr}$ pellet method on a Burker IFS 66V spectrometer in the range of $4000-400 \mathrm{~cm}^{-1}$ with the spectral resolution of $2 \mathrm{~cm}^{-1}$. The FT- Raman spectrum was also recorded in the range of $4000-100 \mathrm{~cm}^{-1}$ using the same instrument with FRA 106 Raman module equipped with $\mathrm{Nd}$ : YAG Laser source operating at $1.064 \mu \mathrm{m}$ with $200 \mathrm{~mW}$ powers and Ge detector. The frequencies of all sharp bands are precise to $2 \mathrm{~cm}^{-1}$. The UV spectrum of the titled compound is recorded with the UV-1700 spectrophotometer. The spectrum is recorded for the spectral wavelength range of 200- 400 $\mathrm{nm}$ with a scanning interval of about $0.2 \mathrm{~nm}$.

\section{B. Quantum chemical calculations}

All the computations on the molecule 3-cyanochromone were performed using the GAUSSIAN 09 software [12] on Pentium IV processor in personal computer. The geometry of the titled compound was optimized using B3LYP functional in combination with cc-pVDZ basis set. The NMR chemical shift was carried out by GIAO method in combination withB3LYP functional and cc-pVDZ basis set. In addition, Mullikan charges and natural charges of the title molecule are also computed using B3LYP method with same basis set. The optimized parameters of the compound 3-cyanochromone were used for harmonic vibrational frequency calculations, resulting in FT-IR and FT-Raman frequencies together with intensity and Raman depolarization ratios. The electronic properties such as NBO and HOMO-LUMO of the titled compound were calculated using timedependent TD-SCF method under the same functional and basis set. From the theoretical calculations the optical properties of the titled compounds such as dipole moment, polarizability and hyper polarizability were predicted.

\section{RESULT AND DISCUSSION}

\subsection{Conformational analysis}

The optimized molecular structure of the present molecule was used for conformational analysis, which was performed by potential energy surface scan techniques using B3LYP, by varying the dihedral angle $20 \mathrm{H}-18 \mathrm{~N}-17 \mathrm{C}-22 \mathrm{H}$ in the steps of $10^{\circ}$ over one complete rotation. The graphical result, total energy (Hartree) verses scan coordinates of the conformer, is presented in Fig 1. The graph clearly shows that conformer at minimum energy level occurs at $175^{\circ}$, with energy value -0.0553 Hartree. This conformer serves as the most stable conformer of the compound. The maximum energy is observed for the conformer at $225^{\circ}$ with energy value -0.0523 Hartree, this is the least stable or most unstable conformer of the compound. The most stable conformer is used for all the computational analysis in the present work.

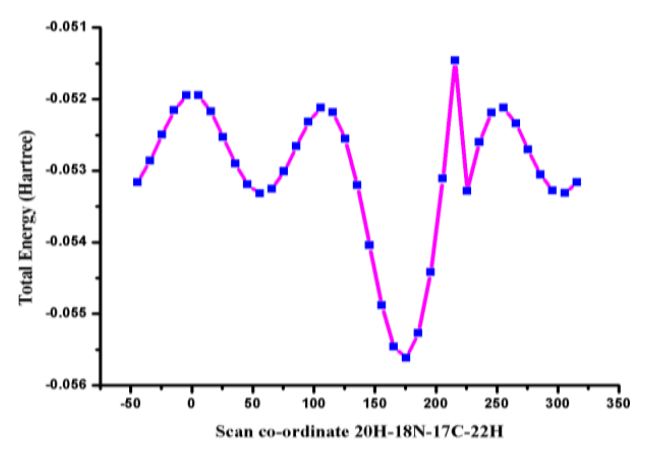

Fig. 1 The potential energy curve of 3-Cyano chromone

\subsection{Molecular geometrical analysis}

The structural analysis of 3-cyano chromone was carried out using B3LYP method and cc-PVDZ basis set for the most stable conformer of the compound. The bond lengths and bond angles of the compound calculated using this method are listed in the Table1. The optimized structure of the compound is shown in Fig 2. The experimental data obtained through single crystal X-ray method for title molecule 


\section{International Journal of Research in Advent Technology, Vol.7, No.5, May 2019 E-ISSN: 2321-9637 \\ Available online at $w w w . i j r a t . o r g$}

reported at an earlier work [13] was used here for the comparison purpose. The theoretical values indicate that the most of the bonds lengths are slightly higher in magnitude than that of the experimental values.

This compound has ten $\mathrm{C}-\mathrm{C}$, five $\mathrm{C}-\mathrm{H}$, three $\mathrm{C}-\mathrm{O}$, and one $\mathrm{C}-\mathrm{N}$ bonds. The $\mathrm{C}-\mathrm{C}$ single bonds are expected to value around $1.45 \AA$ and the $\mathrm{C}=\mathrm{C}$ double bond around 1.35 [14]. In the present molecule, in benzene ring, all the $\mathrm{CC}$ bonds have bond length values between $1.38 \AA-1.40 \AA$. This shows they are neither single bonded nor double bonded, which is due to the conjugation of the electrons among these bonds. The variation in values among them is due to the distribution of electron density within the ring among these bonds. In the case of pyrone ring, the $\mathrm{C} 4-\mathrm{C} 9$ and $\mathrm{C} 9-\mathrm{C} 12$ bonds are found to have length of $1.48 \AA$, this value is higher than the expected range for even $\mathrm{CC}$ single bond, which may be due to the presence of oxygen atoms in this ring. The tendency of oxygen atom is to attract an electron towards itself, hence it redistributes the occupancy of electrons present within this ring. The bond length between $\mathrm{C} 12-\mathrm{C} 13$ is $1.36 \AA$, which is slightly greater than the CC double bond value, this may be due to the presence of cyano group at $\mathrm{C} 12$ and also due to oxygen atom attached in $\mathrm{C} 13$ atom.

According to the literature [15], the CO single bond and double bond are expected to have values $1.35 \AA$ and $1.22 \AA$ respectively. In the present compound, the $\mathrm{CO}$ found at $\mathrm{C} 9-\mathrm{O} 15$ has bond length $1.22 \AA$, which indicates that it is clearly a double bonded, where as other $\mathrm{C}-\mathrm{O}$ bonds, $\mathrm{C} 3-\mathrm{O} 16$ and C13-O16 are found to have values $1.38 \AA$ and $1.35 \AA$ respectively, which are single bonded but slightly deviated from the expected value, which may be due to the conjugation present in the pyrone ring.

All the $\mathrm{CH}$ bonds in the benzene ring structure are expected to be of length $1.08 \AA$ [16]. In the present compound, $\mathrm{CH}$ bonds are having the bond length values between $1.082 \AA$ to $1.088 \AA$. There is only one $\mathrm{C}-\mathrm{H}$ in pyrone ring which is found to be $1.088 \AA$, whereas all other are in benzene ring whose values are closer to expected value. The slight variation is purely due to the changed conjugation of these two rings due to their fusion.

The chromone has only one cyano group. The bond length of the $\mathrm{C} 12-\mathrm{C} 17$ is $1.43 \AA$, which is a single bond $\mathrm{CC}$. The C17-N18 has a bond length value of $1.15 \AA$, it implies the expected triple bond formation happens between $\mathrm{C} \& \mathrm{~N}$ atoms.

The bond angle around each carbon atom is expected to be $120^{\circ}$ [17]. In this molecule the bond angle between C2-C1-C6 single bond and C2-C4-C9 single bond angle are observed to be $120^{\circ}$ as expected, but the other bond angles are varying between $117^{\circ}-122^{\circ}$, which means the bond angle are deviated from the expected value due to the influence of $\mathrm{O}$ atoms and $\mathrm{CN}$ group in the pyrone ring.
The same $120^{\circ}$ angles are expected for all the $\mathrm{CCH}$ bonds, but a small variation of the bond angles are observed between the $\mathrm{CCH}$ bonds, which are due to the variation of electronic conjugation among the CCC bonds. All these $\mathrm{CCC}$ single bond and $\mathrm{CCH}$ single bond angles indicate that the structure of the chromone rings are slightly distorted due to the presence of oxygen and $\mathrm{CN}$ group in the molecules.

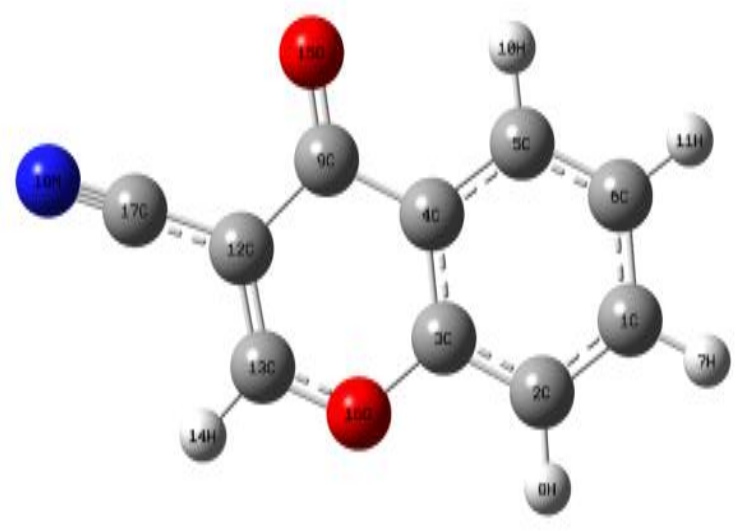

Fig.2 Structure of 3-Cyano chromone

\subsection{Mullikan and Natural charge analysis}

The atomic charge analysis plays important role in the prediction of the properties of the molecule, as the atomic charges affect parameters such as dipole moment, molecular reaction, Vibrational frequency, NMR chemical shift, etc $[18,19]$. The atomic charges are calculated by two methods in the present case for comparison purpose; Mullikan Population Analysis (MPA) and Natural Atomic Charges (NAC), by B3LYP/cc-pVDZ method and the values are listed in the Table 2 and the graphical representation shown in the fig.3.

Carbon atoms in the benzene ring $\mathrm{C} 1, \mathrm{C} 2, \mathrm{C} 3$, C4, C5, C6, are expected to be equally negative except $\mathrm{C} 3$ \& $\mathrm{C} 4$, as the pyrone ring is fused at this bond, but they are predicted to be positive except $\mathrm{C} 3$ in MPA and negatively charged in NAC. The atom $\mathrm{C} 3$ is having negative value $(-0.32)$ in MPA and positive value $(0.33)$ in NAC. C3 in the molecule is found attached to $\mathrm{O}$ atom in the pyrone ring, hence it can be positive as predicted by NAC, as the $\mathrm{O}$ atom is more electro negative than $\mathrm{C}$. The $\mathrm{C} 4$ is predicted by highly positive 2.910 in MPA, while slightly negative -0.18714 in NAC. The $\mathrm{C} 4$ atom is attached to $\mathrm{C}=\mathrm{O}$ group in the pyrone ring, hence all its charge cannot be dragged, as $\mathrm{O}$ is not directly connected, which indicate the NAC prediction is reasonable. Rest of the $\mathrm{C}$ atoms C1, C2, C5 \& C6 are not influenced by the presence of O\&N atoms in substitutional groups, hence they are expected to be equally the presence of $O \& N$ atoms in substitutional groups, hence they are expected to be equally

Carbon atoms present in the pyrone ring are C9, C12, C13 and C17, in which C9 (-0.046) and C17 
(-0.8191)are negative in MPA and positive charge in the NAC, again these two atoms are attached with $\mathrm{O}$ atoms in the ring, hence they can only be positive not negative as predicted by MPA.

$\mathrm{C} 17$ is the carbon atom present in the cyanide group, hence it can be slightly negative but not positive as predicted by NAC. The $\mathrm{C} 13$ has the positive values in the both MPA and NAC. This positive result found due to the presence of oxygen atom in this carbon atom. N18 atom has the moderate charge due to the nature of electronegativity. The nitrogen atom having negative charge on both MPA (-0.1953) and NAC $(-0.3049)$ because of it has more electronegativity than carbon atom. All hydrogen atoms are having a negative charge in MPA and positive in NAC. The NAC prediction in this case is reasonable as the $\mathrm{H}$ atoms can only lose electrons to the $\mathrm{C}$ atoms to which they are attached, as $\mathrm{C}$ atoms are more electronegative compared to $\mathrm{H}$ atoms.

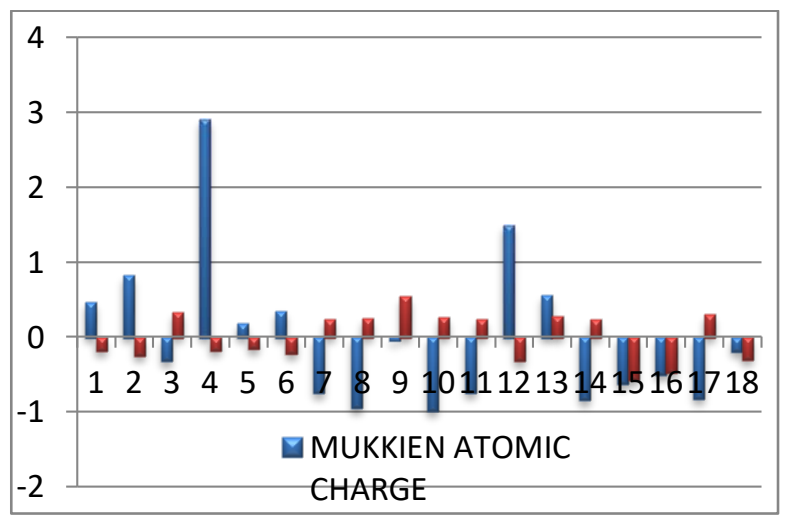

Fig. 3 Mulliken and natural atomic charges of 3-cyano chromone

\subsection{NMR Chemical Shift Assessment}

The Experimental and theoretical values of ${ }^{1} \mathrm{H}$ NMR and ${ }^{13} \mathrm{C}$ NMR chemical shift of 3-cyno chromone are presented in Table 3. Chemical shifts are calculated in ppm and relative to TMS for ${ }^{1} \mathrm{H}$ NMR and ${ }^{13} \mathrm{C}$ NMR spectra. The optimization of the 3-cyano chromone was performed in density functional theory using the hybrid of B3LYP with the basis set cc-pVDZ method, supported by Gauge Including Atomic Orbital (GIAO) technique for finding ${ }^{1} \mathrm{H}$ and ${ }^{13} \mathrm{C}$ chemical shifts.

Aromatic carbons give the spectrum with chemical shift values from 120-130ppm [20]. The experimental chemical shifts in the benzene ring are C1(123.4ppm), C2 (102.9ppm),C3(155.8ppm), C4 (118.5ppm), C5 (118.5ppm), C6 (112.3ppm). The computed chemical shift for carbon atoms C3, C4 and C5 in solvent phase are (147.7ppm), (117.1ppm) and (117.7) respectively. The experimental values are slightly deviated from the theoretical values. Only $\mathrm{C} 1$ is in expected range, all other $\mathrm{C}$ atoms are found to have slightly less value compared to the expected range. The $\mathrm{C} 3$ atom shows the highest value which is in accordance with charge prediction, highly positive, by NAC method, due to the presence of $\mathrm{O}$ atom in the pyrone ring. Since $\mathrm{C} 4$ is not attached directly with $\mathrm{O}$ atom, its value is found to be slightly less than the expected value, which shows it is slightly deshielded, as observed by NAC method. The same reason can also be attributed to C2 (102.9ppm) and C6 (118.5ppm), as their values are also slightly less than the expected range.

In the pyrone ring, there are two $\mathrm{O}$ atoms and one $\mathrm{N}$ atom, which are more electro negative than carbon atoms. Therefore C9 (162.4ppm) and C13 (135.4ppm) which are directly attached to $\mathrm{O}$ atom share values greater than the expected range. $\mathrm{C} 12$ has the chemical shift value (123.4ppm) within the expected range, as it is not directly connected to either $\mathrm{O}$ or $\mathrm{N}$ atoms. $\mathrm{C} 17$ which is connected to $\mathrm{N}$ atom (in Cyano group) is found to have very less value 102 ppm, this is possible because it is not present within the ring where there is a possibility for conjugation, but it is present outside the ring like an aliphatic group. Hence, the chemical shift value must be around 45-65 ppm like methyl/ ethyl carbon, since it is connected to $\mathrm{N}$ atom its shift is enhanced closer to aromatic carbon.

The chemical shift value of ${ }^{1} \mathrm{H}$ atoms in benzene ring is expected between7.0-8.0 ppm [10]. The chemical shifts obtained in this case are found in between 7.805-8.435ppm. Only the two $\mathrm{H}$ atoms in the pyrone ring are found to have values greater $8 \mathrm{ppm}$, which is naturally due to the presence of $\mathrm{O}$ atoms. The $\mathrm{H}$ atoms in the benzene rings are very well within the expected range which shows whose charge distribution is not disturbed by the pyrone ring.



Fig. $4{ }^{13} \mathrm{C}$ NMR Experimental spectrum of 3-Cyano chromone 


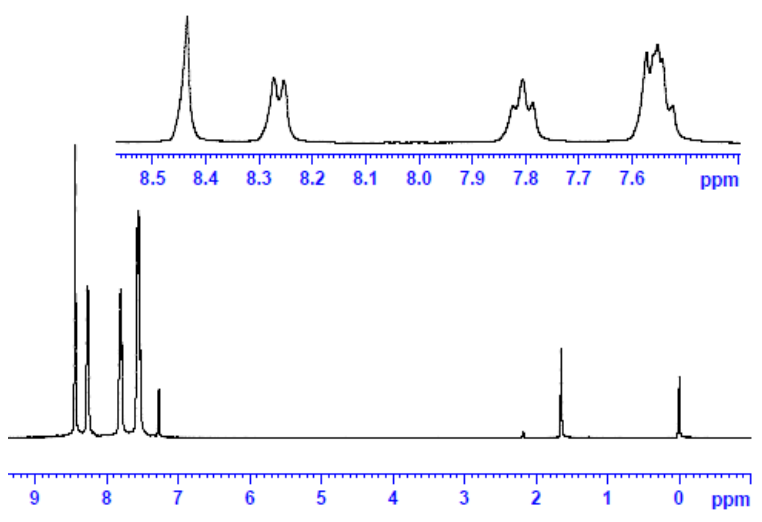

Fig. $5^{1}$ H NMR Experimental spectrum of 3-Cyano chromone

\subsection{Vibrational Analysis}

The 3-cyano chromone, the molecule under investigation has 18 atoms and 48 normal modes of fundamental vibrations. Vibrational wave numbers for all the modes were computed using DFT (B3LYP) methods with cc-pVDZ basis sets and the values along with the experimental values are presented in table 4 . The experimentally recorded and theoretically constructed FT-IR and FT Raman spectra of the 3-cyano chromone compound are shown Fig.6 and 7 respectively.

The calculated wave numbers are found slightly higher than the observed values for the majority of the normal modes. Two factors may be responsible for the discrepancies between the experimental and computed wave numbers; the first is caused by the unpredictable electronic distribution among the different bonds in the molecule and the second reason is the anharmonic nature of the vibrations which cannot be accounted completely by theory. Scaling strategies were used to bring computed wave numbers to coincide with observed values. In this, study, the scaling factor used is 0.956 in accordance with earlier work on similar molecules [21, 22].

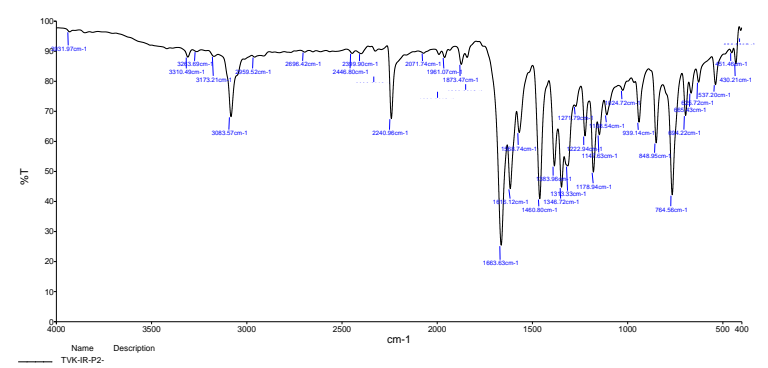

Fig. 6 Experimental FT-IR spectra of 3-Cyano chromone

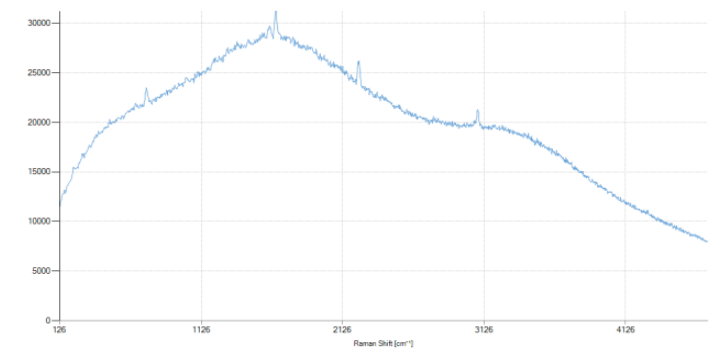

Fig. 7 Experimental Raman spectra of 3-Cyano chromone

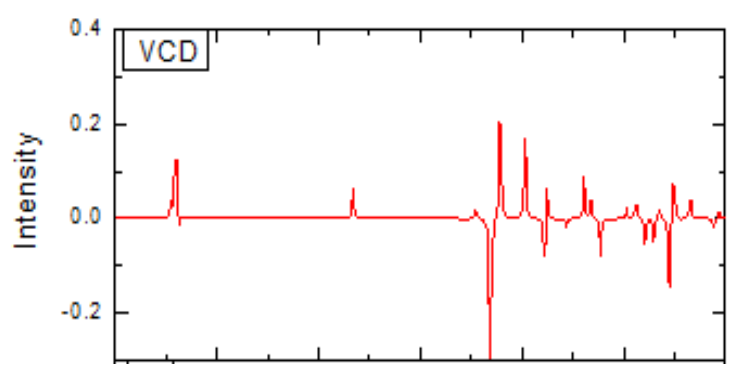

Fig. 8 VCD spectra of 3-Cyano chromone

\section{C-H vibrations}

The aromatic structure represents the presence of $\mathrm{C}-\mathrm{H}$ stretching vibration in the characteristic region of 3100-3000 $\mathrm{cm}^{-1}$ [23]. The C-H stretching modes are usually appears with the strong Raman intensity due to their high polarization. In the present study, the stretching vibrations are predicted at $3183 \mathrm{~cm}^{-1}, 3171 \mathrm{~cm}^{-1}, 3168 \mathrm{~cm}^{-1}, 3157 \mathrm{~cm}^{-1}$, and $3144 \mathrm{~cm}^{-1}$. In the experimental study, the aromatic C-H stretching vibrations were observed at $3263 \mathrm{~cm}^{-1}, 3173$ $\mathrm{cm}^{-1}$ in FT-IR and $3219 \mathrm{~cm}^{-1}, 3200 \mathrm{~cm}^{-1}, 3188 \mathrm{~cm}^{-1}$ in FT-RAMAN respectively. All these values are above the limits meant for aromatic $\mathrm{CH}$, which indicate the pyrone group has greatly influenced these $\mathrm{CH}$ stretching modes, due to the presence of $\mathrm{O}$ and $\mathrm{N}$ atoms.

The $\mathrm{C}-\mathrm{H}$ in plane bending modes usually occurs as strong to weak bands in the region of 1000 $\mathrm{cm}^{-1}$ [24]. Experimental study of this compound manifested $\mathrm{C}-\mathrm{H}$ in plane bending vibration in the region of $1147 \mathrm{~cm}^{-1}, 1024 \mathrm{~cm}^{-1}$ and $981 \mathrm{~cm}^{-1}$ in FT-IR spectrum and $1126 \mathrm{~cm}^{-1}$ and $1015 \mathrm{~cm}^{-1}$ in FT-Raman spectrum.

The C-H out of plane bending vibrations are expected to strong to weak intensity bands in the region of 1000-750 $\mathrm{cm}^{-1}$ [25]. Their frequency depends on the number of adjacent hydrogen atoms in the ring system but they are not significantly affected by the nature of substituents. The recorded FT-IR spectrum of this molecule showed bands at $848 \mathrm{~cm}^{-1}, 764 \mathrm{~cm}^{-1}$ while its FT-RAMAN spectrum manifested bands at 888 $\mathrm{cm}^{-1}, 820 \mathrm{~cm}^{-1}, \mathrm{~cm}^{-1}, 782 \mathrm{~cm}^{-1}, 735 \mathrm{~cm}^{-1}$. Their corresponding computed values were noted at $884 \mathrm{~cm}^{-1}$ to $743 \mathrm{~cm}^{-1}$ respectively. 
The C-C-H torsion vibrations are appeared at $408 \mathrm{~cm}^{-1}, 374 \mathrm{~cm}^{-1}, 287 \mathrm{~cm}^{-1}$ respectively and the FT-IR can be observed at $404 \mathrm{~cm}^{-1}$.

\section{$C=C$ and $C-C$ vibrations}

The $\mathrm{C}-\mathrm{C}$ stretching vibrations are very much important in the spectrum of benzene and also pyrone.

In the benzene ring, the $\mathrm{C}=\mathrm{C}$ and $\mathrm{C}-\mathrm{C}$ stretching vibrations are generally observed between $1600 \mathrm{~cm}^{-1}$ to $1500 \mathrm{~cm}^{-1}$ and $1500 \mathrm{~cm}^{-1}$ to 1400 $\mathrm{cm}^{-1}[26]$. In the present compound the benzene ring $\mathrm{C}=\mathrm{C}$ and $\mathrm{C}-\mathrm{C}$ stretching vibration were appeared at $1635 \mathrm{~cm}^{-1}, 1624 \mathrm{~cm}^{-1}, 1473 \mathrm{~cm}^{-1}, 1463 \mathrm{~cm}^{-1}, 1370 \mathrm{~cm}^{-1}$, and $1360 \mathrm{~cm}^{-1}$ by B3LYP/cc-pVDZ method. In recorded spectrum, these are at $1663 \mathrm{~cm}^{-1}, 1661 \mathrm{~cm}^{-1}$, $1460 \mathrm{~cm}^{-1}, 1383 \mathrm{~cm}^{-1}$ in FT-IR and $1497 \mathrm{~cm}^{-1}, 1411 \mathrm{~cm}^{-1}$ and $1376 \mathrm{~cm}^{-1}$ in FT RAMAN. All the CC vibration in the benzene ring was within the observed range.

In the pyrone ring, the $\mathrm{C}=\mathrm{C}$ and $\mathrm{C}-\mathrm{C}$ stretching vibration is observed in the region of $1586 \mathrm{~cm}^{-1}$ and $13317 \mathrm{~cm}^{-1}, 1263 \mathrm{~cm}^{-1}$ respectively. In experimentally, $\mathrm{C}=\mathrm{C}$ and $\mathrm{C}-\mathrm{C}$ stretching is appeared at $1568 \mathrm{~cm}^{-1}, 1346 \mathrm{~cm}^{-1}, 1271 \mathrm{~cm}^{-1}$ in FT IR spectrum.

The C-C stretching vibration in the external group of cyano group can be observed at $1222 \mathrm{~cm}^{-1}$ and the FT IR spectrum of C-C is appeared at $1222 \mathrm{~cm}^{-1}$. The C-C out of plane bending can be founded at $694 \mathrm{~cm}^{-1}$ in the FT-IR.

The C-C-C in plane bending in trigonal vibration mode in molecule can be founded at 242 $\mathrm{cm}^{-1}, 214 \mathrm{~cm}^{-1}, 132 \mathrm{~cm}^{-1}, 130 \mathrm{~cm}^{-1}$ and $62 \mathrm{~cm}^{-1}$ in the computed values.

\section{$C=O$ and $C-O$ Vibrations}

In $\mathrm{C}-\mathrm{O}$ group, the absorption is sensitive for both carbon and oxygen atom. Normally the C-O stretching vibration occurs in the range $1150 \mathrm{~cm}^{-1}$ [27]. The intensity of the chromone group increases due to the conjugation or formation of hydrogen bonds. The increases in conjugation, which increases the intensity of Raman lines as well as the IR band intensities. According o the above facts, there are two theoretical wave numbers are observed in the pyrone ring at $1178 \mathrm{~cm}^{-1}$ and $1169 \mathrm{~cm}^{-1}$. The corresponding experimental FT RAMAN bands were observed at $1190 \mathrm{~cm}^{-1}$ and FT-IR is appeared at $1178 \mathrm{~cm}^{-1}$. The torsion C-C-O bending vibration mode is appeared at $501 \mathrm{~cm}^{-1}$ in FT RAMAN and $451 \mathrm{~m}^{-1}$ in FT IR, hence the calculated mode at $484 \mathrm{~cm}^{-1}$ and $455 \mathrm{FT} \mathrm{cm}^{-1}$ respectively.

The stretching mode of $\mathrm{C}=\mathrm{O}$ in the pyrone ring is expected in the range at $1750 \mathrm{~cm}^{-1}[18]$. The theoretical study this title compound showed only one $\mathrm{C}=\mathrm{O}$ stretching band at $1703 \mathrm{~cm}^{-1}$ with $\mathrm{PED}$ contribution of $83 \%$. In experimentally the FT RAMAN spectrum was observed at $1751 \mathrm{~cm}^{-1}$. The $\mathrm{C}=\mathrm{O}$ in plane bending mode is founded at $927 \mathrm{~cm}^{-1}$ in the computed values and the corresponding FT-IR spectrum of $\mathrm{C}=\mathrm{O}$ in plane bending appeared at $939 \mathrm{~cm}^{-1}$. The $\mathrm{C}=\mathrm{O}$ out of plane bending vibration in FT IR spectrum can be observed at $665 \mathrm{~cm}-1$ and the calculated value at $665 \mathrm{~cm}^{-1}$. The $\mathrm{C}-\mathrm{C}=\mathrm{O}$ torsion bending were computed at the range of $549 \mathrm{~cm}^{-1}$ and $534 \mathrm{~cm}^{-1}$ respectively. The experimental FT-RAMAN and FT-IR values are obtained at $560 \mathrm{~cm}^{-1}$ and 537 $\mathrm{cm}^{-1}$.

\section{C $\equiv N$ Vibrations}

In this titled molecule stretching vibrations of $\mathrm{C} \equiv \mathrm{N}$ vibration mode was observed in $2300 \mathrm{~cm}^{-1}$ in the computed value and the FT IR spectra were founded in $2240 \mathrm{~cm}^{-1}$. The in-plane bending have the range at $711 \mathrm{~cm}^{-1}$ in the calculated value and the corresponding experimental in plane vibration at $694 \mathrm{~cm}-1$ is observed in FT-IR spectra. The out of plane bending of $\mathrm{CN}$ is computed in the range $527 \mathrm{~cm}^{-1}$ and in FT-RAMAN is $511 \mathrm{~cm}^{-1}$.

The $\mathrm{C}-\mathrm{C} \equiv \mathrm{N}$ out of plane bending vibration can be calculated by the computed values is $427 \mathrm{~cm}^{-1}$, then FT-IR obtained at $430 \mathrm{~cm}^{-1}$ and Ft-RAMAN is $423 \mathrm{~cm}^{-1}$ respectively.

\subsection{NBO Analysis}

The bonding and non-bonding (anti-bonding) interactions can be quantitatively described in terms of the NBO (Natural bonded orbitals) analysis, which can be predicted by in terms of the second order perturbation interaction energy $\left[\mathrm{E}^{(2)}\right][28,29]$. This energy represents the estimation of the off diagonal NBO Fock matrix elements. It can be deduced from the second order perturbation approach [30]

$$
E^{(2)}=\Delta E_{i j}=q_{i} \frac{F(i, j)^{2}}{\varepsilon_{j}-\varepsilon_{i}}
$$

Where,

$\mathrm{Q}_{\mathrm{i}}$ is the donor orbital occupancy, $\varepsilon_{\mathrm{i}}$ and $\varepsilon_{\mathrm{j}}$ are diagonal elements (orbital energies) and $F(i, j)$ is the off diagonal NBO Fock matrix elements.

In this analysis, the occupancies, from bonding to anti-bonding levels, and their energy levels were calculated and presented in the Table 5. The highly probable $\pi-\pi^{*}$ and $\mathrm{n}-\pi^{*}$ transitions are observed between $\mathrm{C}-\mathrm{C}, \mathrm{C}-\mathrm{O}, \& \mathrm{C}-\mathrm{N}$ bonding orbitals with adjacent anti-bonding orbitals. The highest $\pi-\pi^{*}$ transitions in 3-cyano chromone based on the E2 values in descending order can be listed as $\mathrm{C} 1-\mathrm{C} 2$ to C3-C4 $\left(\pi-\pi^{*}, 22.29 \mathrm{kcal} / \mathrm{mol}\right), \mathrm{C} 5-\mathrm{C} 6$ to $\mathrm{C} 1-\mathrm{C} 2\left(\pi-\pi^{*}\right.$, $21.56 \mathrm{kcal} / \mathrm{mol}), \mathrm{C} 3-\mathrm{C} 4$ to $\mathrm{C} 9-\mathrm{O} 15\left(\pi-\pi^{*}, 20.58\right.$ $\mathrm{kcal} / \mathrm{mol}), \mathrm{C} 5-\mathrm{C} 6$ to $\mathrm{C} 3-\mathrm{C} 4\left(\pi-\pi^{*}, 18.83 \mathrm{kcal} / \mathrm{mol}\right)$, $\mathrm{C} 3-\mathrm{C} 4$ to $\mathrm{C} 1-\mathrm{C} 2\left(\pi-\pi^{*}, 16.41 \mathrm{kcal} / \mathrm{mol}\right)$, and $\mathrm{C} 1-\mathrm{C} 2$ to C5-C6 $\left(\pi-\pi^{*}, 16.26 \mathrm{kcal} / \mathrm{mol}\right)$.

The highest $\pi-\pi^{*}$ stabilization energies in pyrone ring are $\mathrm{C} 12-\mathrm{C} 13$ to $\mathrm{C} 9-\mathrm{O} 15\left(\pi-\pi^{*}, 21.38 \mathrm{kcal} / \mathrm{mol}\right)$, C12-C13 to C17-N18 ( $\left.\pi-\pi^{*}, 17.77 \mathrm{kcal} / \mathrm{mol}\right)$ and the $\mathrm{n}-\pi^{*}$ stabilization energies are $\mathrm{O} 16$ to $\mathrm{C} 12-\mathrm{C} 13\left(\mathrm{n}-\pi^{*}\right.$, $35.74 \mathrm{kcal} / \mathrm{mol}), \mathrm{O} 16$ to $\mathrm{C} 3-\mathrm{C} 4$ (n- $\pi^{*}, 25.27$ $\mathrm{kcal} / \mathrm{mol}), \mathrm{O} 15$ to C9-C12 (n- $\left.\pi^{*}, 21.95 \mathrm{kcal} / \mathrm{mol}\right), \mathrm{O} 15$ 
to $\mathrm{C} 4-\mathrm{C} 9\left(\mathrm{n}-\pi^{*}, 19.87 \mathrm{kcal} / \mathrm{mol}\right)$, and N18 to $\mathrm{C} 12-\mathrm{C} 17$ (n- $\left.\pi^{*}, 12.47 \mathrm{kcal} / \mathrm{mol}\right)$.

Therefore the top ten highly probable electronic transitions, according to their stabilization energy can be listed as follows: 1 . O16 to C12-C13 (n$\left.\pi^{*}, 35.74 \mathrm{kcal} / \mathrm{mol}\right), 2$. O16 to $\mathrm{C} 3-\mathrm{C} 4\left(\mathrm{n}-\pi^{*}, 25.27\right.$ $\mathrm{kcal} / \mathrm{mol}), 3 . \mathrm{C} 1-\mathrm{C} 2$ to $\mathrm{C} 3-\mathrm{C} 4\left(\pi-\pi^{*}, 22.29 \mathrm{kcal} / \mathrm{mol}\right)$, 4. $\mathrm{O} 15$ to $\mathrm{C} 9-\mathrm{C} 12\left(\mathrm{n}-\pi^{*}, 21.95 \mathrm{kcal} / \mathrm{mol}\right), 5 . \mathrm{C} 12-\mathrm{C} 13$ to $\mathrm{C} 9-\mathrm{O} 15\left(\pi-\pi^{*}, 21.38 \mathrm{kcal} / \mathrm{mol}\right), 6 . \mathrm{C} 3-\mathrm{C} 4$ to $\mathrm{C} 9-\mathrm{O} 15$ $\left(\pi-\pi^{*}, 20.58 \mathrm{kcal} / \mathrm{mol}\right), 7.015$ to $\mathrm{C} 4-\mathrm{C} 9\left(\mathrm{n}-\pi^{*}, 19.87\right.$ $\mathrm{kcal} / \mathrm{mol}), 8$. C5-C6 to $\mathrm{C} 3-\mathrm{C} 4\left(\pi-\pi^{*}, 18.83 \mathrm{kcal} / \mathrm{mol}\right)$, 9. $\mathrm{C} 3-\mathrm{C} 4$ to $\mathrm{C} 1-\mathrm{C} 2\left(\pi-\pi^{*}, 16.41 \mathrm{kcal} / \mathrm{mol}\right)$, and 10 . $\mathrm{C} 1-\mathrm{C} 2$ to $\mathrm{C} 5-\mathrm{C} 6\left(\pi-\pi^{*}, 16.26 \mathrm{kcal} / \mathrm{mol}\right)$. All these transitions though theoretically favorable, only a few transitions will be allowed by the selection rules, which can be identified by the oscillator strength and HOMO- LUMO contribution, as it is done in the following section.

\subsection{UV-Visible Analysis}

The UV-Visible spectrum of the 3-cyano chromone is recorded in the range of 200-400 nm in Ethanol solvent phase [31]. The theoretical UV-Vis studies which analyze various possible electronic excitation, wavelength, oscillation strength and also major FMO contribution in both gas phase and a ethanol phase is carried out using TD-SCF method along with B3LYP/CC-PVDZ combination, all these parameters both experimental and theoretical are presented in Table 6.

The theoretically simulated spectrum in ethanol phase shows a broad hump over the wavelength regionbetween $309 \mathrm{~nm}$ to $202 \mathrm{~nm}$ with energy gap ranging from $3.642 \mathrm{eV}$ to $5.472 \mathrm{eV}$. However, the oscillator strength and HOMO to LUMO contribution shows that only the second transition in the list $\mathrm{O} 16$ to $\mathrm{C} 3-\mathrm{C} 4\left(\mathrm{n}-\pi^{*}, 25.27 \mathrm{kcal} / \mathrm{mol}\right)$ causes the peak value in the hump. This value indicates that this is a $n-\pi^{*}$ transition which takes place at the wavelength $289 \mathrm{~nm}$ theoretically and $270 \mathrm{~nm}$ experimentally. The other transitions which have considerable oscillator strengths value among $\pi-\pi^{*}$ transitions, are the sixth and seventh transition in the list C3-C4 to C9-O15 $\left(\pi-\pi^{*}, 20.58 \mathrm{kcal} / \mathrm{mol}\right)$, and $\mathrm{O} 15$ to $\mathrm{C} 4-\mathrm{C} 9\left(\mathrm{n}-\pi^{*}, 19.87 \mathrm{kcal} / \mathrm{mol}\right)$, but the HOMO LUMO contribution for this transition are found to be very low, hence these transitions cannot take place in the spectrum. But, indeed these transitions have appeared in the spectrum at wavelength 234 and 228 $\mathrm{nm}$, which may be due to the fact that all these transitions originate from the same location in the molecule.

The same trend is also observed in gas phase also, except a small difference in absorption wavelength. The sixth transition which is found active in ethanol phase is found inactive in gas phase. These two observations may be attributed to the solvent effect in this molecule. The major contributions of the transitions were designated with the aid of Swizaed program [23]. From the calculated absorption spectra, the maximum absorption wavelength corresponds to the electronic transition from the HOMO to LUMO with $88 \%$ contribution in gas phase and from HOMO-LUMO 91\% contribution in ethanol phase. The other major contribution of varies wave length are listed in the table 6 .
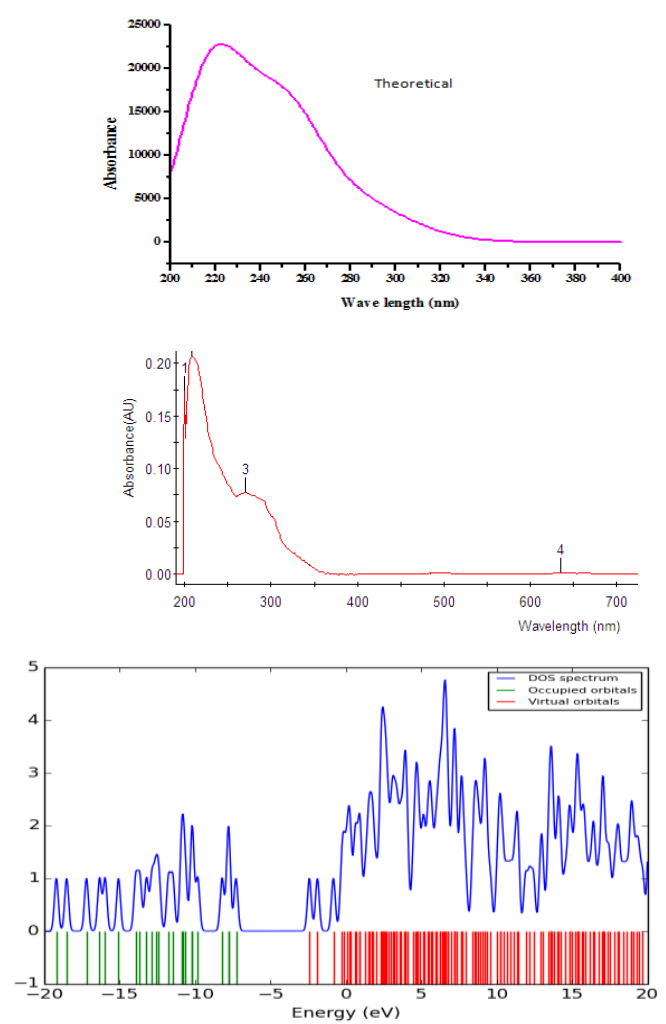

Fig. 9 Theoretical and Experimental UV-Vis and DOS Spectra of 3-Cyano chromone

\subsection{HOMO-LUMO Analysis}

The highest occupied molecular orbital (HOMO) donates electrons while the lowest unoccupied molecular orbital (LUMO) accepts electrons from the orbitals. These orbitals are known as frontier molecular orbital. The frontier molecular orbitals are very much useful for studying the electric and optical properties of the organic molecules. The energy gap (eV) between the HOMO and LUMO is very important parameter to study the chemical behavior of a compound [32][33]. Also, the energy gap between HOMO-LUMO of the molecules determines whether it can have high reactivity or low kinetic stability [34]. The calculated HOMO and LUMO energies of the 3-cyano chromone molecule was founded to be -0.2734 and -0.0247 , respectively, using the DFT method of B3LYP with the basis set of CC-PVDZ and the energy gap between HOMO-LUMO was $-0.2095 \mathrm{eV}$. The HOMO-LUMO energy gap and different reactivity descriptors of molecule in both levels are presented in the table. The negative charge was represented as red and the positive charge was represented by green colour. It showed the 
spread of HOMO over the chromone ring of oxygen and some part of the chromone ring while LUMO was located. The HOMO-LUMO energy gap revels the unlimited possible charge transfer within the molecule and hence its possible chemical and biological reactivity with respect to the transition, there are ten maximum computed wavelengths 309.94, 289.84, $268.78,254.86,254.27,234.97,228.32,215.58$, 205.52, 202.91nm, which correspond to the major contribution of H-1->LUMO (95\%), HOMO->LUMO (91\%), H-2->LUMO (43\%), H-2->LUMO (48\%), H-1->L+1 (97\%), H-3->LUMO (82\%), H-3->L+1 (16\%), H-3->L+1 (50\%), H-1->L+2 (98\%), H-3->L+1 $(11 \%)$ in the solvent phase. The transition can be accounted for the non-bonding transition (n- $\left.\pi^{*}\right)$ of the lone pair in the molecule. Frontier molecular orbital of 3 -cyano chromone is shown in the fig. 10.

In this study of molecule have be calculated some values such that Electronegativity, global hardness ( $\eta$ ), Global softness (s), Electrophilicity index $(\omega)$, Dipole moment $(\mu)$. According to Koopman's theorem [35] $\left(\mathrm{E}_{\mathrm{HOMO}}\right)$ is represents Ionization Potential (IP) and ( $\left.\mathrm{E}_{\mathrm{LUMO}}\right)$ is represents Electron Affinity (EA).

\section{Electronegativity $(\chi)$ :}

The electronegativity is defined by Mullikan as the average of ionization potential (IP) and electron affinity (EA)[36].

\section{Global Hardness $(\eta)$ :}

$$
\chi=-\frac{1}{2}\left(E_{H}+E_{L}\right)
$$

The hardness of a molecule is related to the gap between the HOMO and LUMO orbital's. The larger HOMO-LUMO energy gap the harder will be the molecule chemical hardness can be calculated as follows [37]

\section{Global Softness (s)}

$$
\eta=-\frac{1}{2}\left(E_{H^{-}}-E_{L}\right)
$$
[38]

The global softness is the inverse of global softness

$$
\mathrm{S}=-2\left(\mathrm{E}_{\mathrm{H}}-\mathrm{E}_{\mathrm{L}}\right)
$$

Electrophilicity Index $(\omega)$

Parr et al., have introduced global electrophilicity index which measures the propensity of a species to accept electrons. It can be calculated by using the electronegativity $(\chi)$ and chemical hardness $(\eta)$ [39]

$$
\omega=\frac{\chi 2}{2 \eta}
$$

The electronegativity is a measure of attraction of an atom for electrons in a covalent bond has found to be 0.1490 . The global hardness is a measure the resistance of an atom or a group of atoms to receive electrons and is equal to reciprocal of global hardness and it is found to be 0.2430 . The global softness describes the capacity of an atom or a group of atoms to receive electrons and is equal to reciprocal of global hardness and it is found to be 0.4974 . The electrophilicity index is a measure of lowering of total energy due to the maximal electron flow between the donors and the acceptors and it is found to be 0.0893 . The dipole moment is found to be 7.5593.

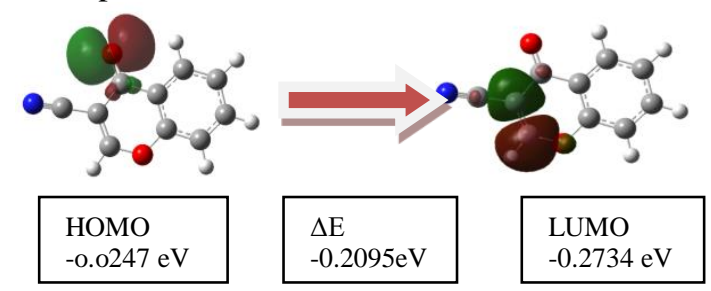

Fig. 10 Frontier molecular orbitals of 3-Cyano chromone

\subsection{NLO Properties}

Organic and semi-organic NLO materials have been subjected to intense research due to their possible applications in wide range of technologies, such as optical communication, optical computing and data storage, etc. The first order hyperpolarizability is a third rank tensor that can be described by a $3 \times 3 \times 3$ matrix. The 18 components of the $3 \mathrm{D}$ matrix can be reduced to 10 components due to Kleinman symmetry [40]. The total static dipole moment $(\mu)$, the mean polarizability $\left(\alpha_{0}\right)$ and the mean first order hyperpolarizability $\left(\beta_{0}\right)$, using the $\mathrm{x}, \mathrm{y}, \mathrm{z}$ components are defined as

$$
\begin{gathered}
\mu=\left(\mu_{x}^{2}+\mu_{y}^{2}+\mu_{z}^{2}\right)^{1 / 2} \\
\alpha_{0}=\frac{\alpha_{x x}+\alpha_{y y}+\alpha_{z z}}{3} \\
\beta_{0}=\left(\beta_{x}^{2}+\beta_{y}^{2}+\beta_{z}^{2}\right)^{1 / 2}
\end{gathered}
$$

$$
\begin{aligned}
& \Delta \alpha=1 / \sqrt{ } 2\left[\left(\alpha_{\mathrm{xx}}-\alpha_{\mathrm{yy}}\right)^{2}+\left(\alpha_{\mathrm{yy}}-\alpha_{\mathrm{zz}}\right)^{2}+\left(\alpha_{\mathrm{zz}}-\alpha_{\mathrm{xx}}\right)^{2}\right. \\
& \left.+6 \alpha_{\mathrm{xy}}^{2}+6 \alpha_{\mathrm{xz}}^{2}+6 \alpha_{\mathrm{yz}}^{2}\right]^{1 / 2} \\
& <\beta>=\left[\left(\beta_{\mathrm{xxx}}+\beta_{\mathrm{xyy}}+\beta_{\mathrm{xzz}}\right)^{2}+\left(\beta_{\mathrm{zyy}}+\beta_{\mathrm{yzz}}+\beta_{\mathrm{yxx}}\right)^{2}+\left(\beta_{\mathrm{zzz}}+\right.\right. \\
& \left.\left.\beta_{\mathrm{zxx}}+\beta_{\mathrm{zyy}}\right)^{2}\right]^{1 / 2}
\end{aligned}
$$

The NLO properties of 3-cyano chromone compound were calculated using B3LYP/cc-PVDZ method. The electronic dipole moment $(\mu)$ (Debye), polarizability $(\alpha)$ and first hyperpolarizability $(\beta)$ of 3 -cyano chromone are given in table 8 . Standard value for urea $\left(\boldsymbol{\mu}=1.3732\right.$ Debye, $\left.\boldsymbol{\beta}_{0}=1.584 \times 10^{-30} \mathrm{esu}\right)$ : esu-electrostatic unit. The dipole moment $(\mu)$ and first order hyperpolarizability $\left(\beta_{0}\right)$ values are calculated at 7.5599 Debye and $167.24 * 10^{-33} \mathrm{esu}$, respectively. These results show that, the $\beta_{0}$ values of studied molecules are higher than the magnitude of urea which is used frequently as a threshold value for comparative purposes [41,42]. This high value of hyperpolarizability may be due to the presence of electro-negative nitro group and $\pi$ bonds. The theoretical calculation of $\beta$ components is very useful as this clearly indicates the direction of charge 


\section{Available online at www.ijrat.org}

delocalization. Domination of particular component indicates on a substantial delocalization of charges in this direction. The $\beta_{\mathrm{xxx}}$ direction shows largest value of hyperpolarizability which insists that the delocalization of electron cloud is more that direction than other directions. Therefore, the largest $\beta_{\mathrm{xxx}}$ value indicates charge delocalization is perpendicular to the bond axis and the involvement of $\pi$ orbitals in intra-molecular charge transfer process. Hence the molecule has good NLO activity.

\subsection{MEP (molecular electrostatic potential) Analysis}

The molecular electrostatic potential (MEP) is related to the electron density and is a very useful parameter to understanding sites for electrophilic and nucleophilic reactions as well as hydrogen bonding interactions [43, 44]. The different values of MEP surface are represented by different colors: red, blue and green represent the regions of most negative, most positive and zero electrostatic potential, respectively. The red color represents negative electrostatic potential corresponds to an attraction of the proton by the aggregate electron density in the molecule, while the positive electrostatic potential corresponds to a repulsion of the proton by the atomic nuclei (blue).From the MEP surface is evident that the negative charge covers the $\mathrm{C}=\mathrm{O}$ group and $\mathrm{C} \equiv \mathrm{N}$ group and the positive region is over the remaing part of the chromone group in the titled compound. The MEP surface of the title molecule is shown in Fig.11.

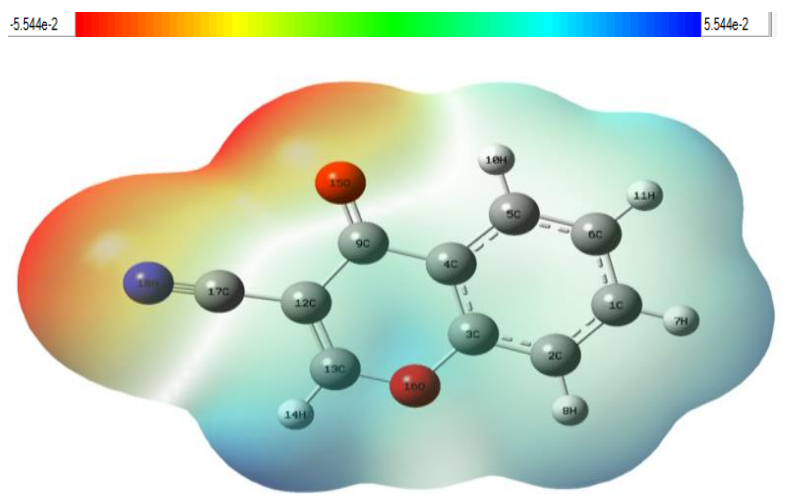

Fig. 11 MEP surface of 3-Cyano chromone

\subsection{Thermodynamic properties}

The thermodynamic functions of this 3-cyano chromone compound at different temperatures were calculated at B3LYP/cc-pVDZ level and were listed in the Table 9. The entropy, specific heat capacity and enthalpy were varied with respect to temperature from $100 \mathrm{~K}$ to $300 \mathrm{~K}$. The variation of the parameters was found to be linear and sustained up to the maximum temperature. This shows that the consistent chemical stability of this compound. Similarly, the Gibbs free energy was observed to be linear with respect to temperature. The chemical reaction can be possible when the Gibbs free energy of the molecular system decreases. It indicates that the Gibbs free energy is negative or less than zero, the chemical reaction is continued. If it is positive, the reaction will be stopped. In this case, the Gibbs energy was found to be still negative up to $300 \mathrm{~K}$ and it was concluded that, the present compound was chemically strong and active.
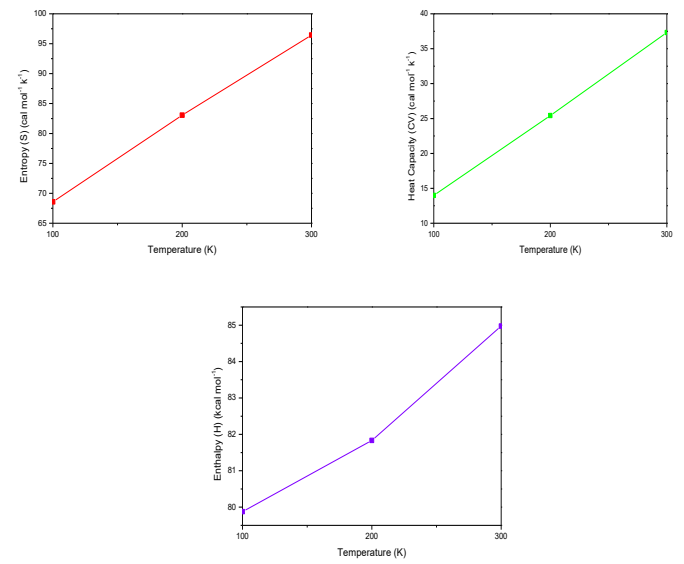

Fig. 12 Correlation graph of thermodynamic properties at different temperature of 3-Cyano chromone

\subsection{Reduced Density Gradient (RDG) analysis}

The RDG is obtained from electron density as a dimensionless quantity of its first gradient was developed [45].

$$
\operatorname{RDG}(\mathrm{r})=\frac{1}{3\left(3 \pi r^{2}\right)^{\frac{1}{3}}}+\frac{\Delta^{2} \rho(r)}{\rho(r)^{\frac{4}{3}}}
$$

The plot of $\rho(\mathrm{r})$ in $\mathrm{x}$-axis and $\lambda_{2}$ in $\mathrm{y}$-axis provides the nature and strength of interaction in the molecule using color code interaction. The RDG analysis was carried out by an isosurface, steric effect and $\mathrm{H}$-bond is plotted by using Multiwfn software [46]. The steric effect is representing the strong repulsion and $\mathrm{H}$-bond, isosurface are strong attracted that appear in the ring system and the strong Vander Walls interaction are located in cyano and $\mathrm{C}=\mathrm{O}$ atom in the ring system.

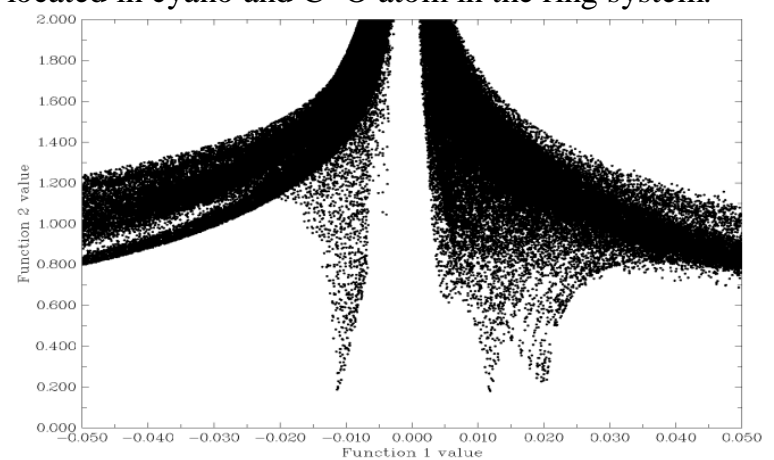

Fig. 13 Reduced Density Gradient of 3-Cyano chromone 


\subsection{Electron Localization Function (ELF) analysis}

Electron localization function analysis represent $\mathrm{n}(\mathrm{r})$ is scalar function and Fermi hole curvature [47]. In this calculation were found at kinetic energy density using Pauli relation. In present graphical 2D \& 3D image representation fig 14, illustrated using Multiwfn software [46]. These atoms play an important role in the determined denote the surface of core i.e. blue colour represent neutral charge red color hole represent negative charge covers the $\mathrm{C}=\mathrm{O}$ group and $\mathrm{C} \equiv \mathrm{N}$ group. The positive region is over the reaming part of the chromone group in the titled compound.
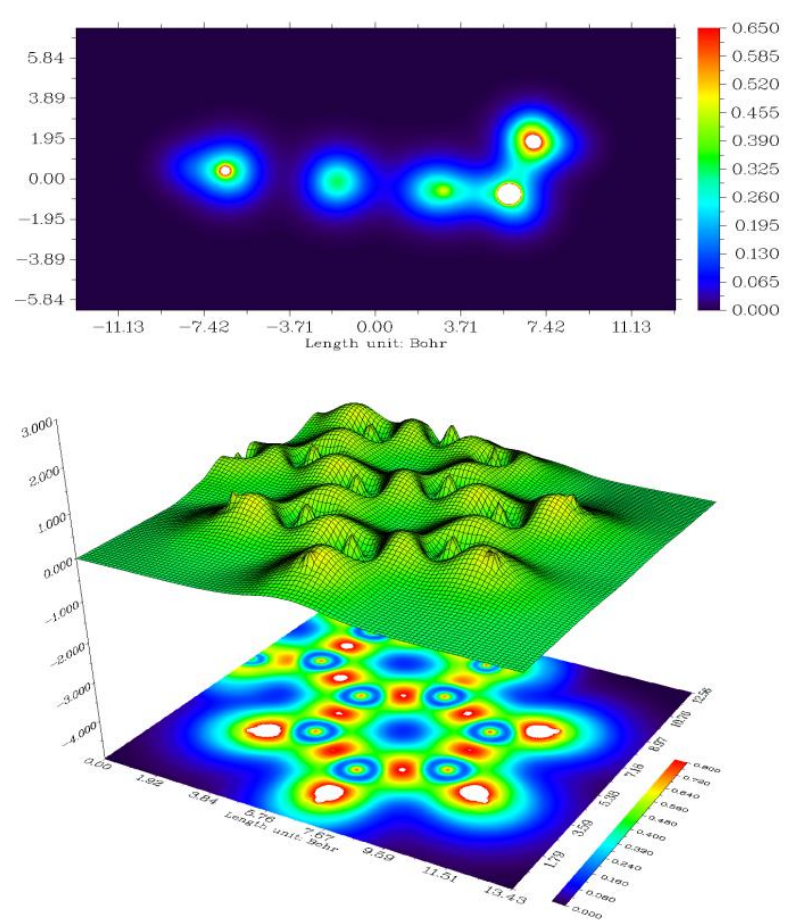

Fig. 14 2D \& 3D Electron Localization Function of 3-Cyano chromone

\subsection{Docking Analysis}

The normal resolution crystal structure of Human SULT1A1 bound to PAP protein was used as a target protein in (protein ID: 3U3M) [48] and auto dock 4.0 software package [49] was utilized to perform docking study. The protein structures were prepared with the help of Auto dock tools graphical [49] user intergace. polar hydrogen was added to the protein, atomic charges calculation kollman method and Lamarckian genetic Algorithm (LGA) were utilized auto dock package.

In our protein data bank molecule (ligand) was created by using optimized molecule. The energies were defined to add resides of active side with the use

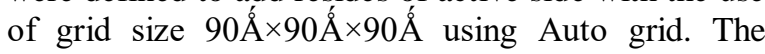

Lamarckian Genetic Algorithm is implemented in Auto dock were employed for docking [49].The Auto dock binding energy ( $\mathrm{kcal} / \mathrm{mol})$, inhibition constants, intermolecular energy were computed and Tabulated in Table 10, the best lowest energy docked position of the ligand with protein are illustrated in Fig.15.

The best result i.e. lowest binding result are shown in 3U3Mprotein exhibit the lower binding energy (5.52 $\mathrm{kcal} / \mathrm{mol}$ ) with inhibition constant value of $89.53(\mu \mathrm{m})$. The analysis shows the PHE 81 form H-bond with cyano group existence of the protein-ligand interact with the bond length of $3.0 \AA$ and PRO 90 form $\mathrm{H}$-Bond with $\mathrm{C}=\mathrm{O}$ existence of the protein-ligand interact with the bond length of 3.1 Á. Here, structural, protein and ligand were employed to obtain deep understanding of the molecular basis for the broad specificity and substrate inhibition of SULT1A1.We found that active site binding of protein-ligand site active in hydrogen bonding for food resolution.

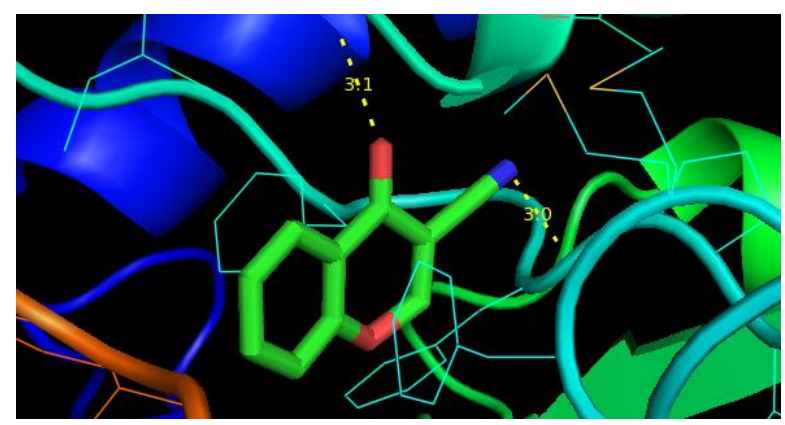

Fig. 15 Docking analysis of 3-Cyano chromone

\section{CONCLUSION}

The molecular spectroscopic and the theoretical tools were properly used to predict the physical, chemical and biological properties of the compound 3-cyano chromone and following observation and conclusion are made;

The optimized structure of the title compound was performed using B3LYP/cc-pVDZ basis set compare with the XRD values are determined the most stable conformer of the compound, Such as C-C, C-H, $\mathrm{C}-\mathrm{O}$ and $\mathrm{C}-\mathrm{N}$.

The NMR analysis, ${ }^{13} \mathrm{C}$ NMR chemical shift values of benzene ring shows $120-130 \mathrm{ppm}$. The values are slightly varied due to the pyrone ring in that benzene ring. In the pyrone, the chemical shift founded at $164.8 \mathrm{ppm}$ in theoretical and $162.4 \mathrm{ppm}$ in experimentally. The ${ }^{1} \mathrm{H}$ NMR chemical shift in both benzene and pyrone ring appeared to be at 7 to $8 \mathrm{ppm}$.

The FT IR and FT RAMAN spectra of 3-cyano chromone have been recorded and the detailed vibrational harmonic frequencies, PED assignments are compared with the experimental data. Considerable level of correlation has been noticed. The detailed PED\% analysis of the compound showed a good agreement with the experimental data. 
The NBO analysis reflects the charge transfer occur within the molecule. In this study, the electronic transitions from bonding to antibonding levels were analyzed. The intermolecular hyper conjugative interactions are caused by the orbital overlapping between $\pi-\pi^{*}$ and $\mathrm{n}-\pi^{*}$ (C-C, C-H, C-O and C-N) bonds orbital.

The UV-Visible spectra indicate that the entire electronic transition shifted bathochromically due to the substitutional effects. The calculated absorption maxima values have been founded to be in gas phase and the ethanol phase.

The calculated HOMO and LUMO along with their plot has been presented for understanding of charge transfer occurring with the compound. The HOMO and LUMO energies were used to semiquantitavely estimate the ionization potential, electronegativity, global hardness and softness, electrophilicity index and chemical potential.

The non-linear optical behavior of the molecule was predicted first order hyperpolarizabilities. The cyano functional group changes in the charge distribution both the inside and outside the pyrone ring causing large dipole moment and polarizability values.

The Molecular Electrostatic Potential founded the positive and negative electrostatic potential of the title compound. The electron density corresponds to an attraction and repulsion with the proton by the nuclei.

The thermodynamic parameter such as entropy, heat capacity and the enthalpy can be calculated using B3LYP/cc-pVDZ function. This parameter was performed by different temperature from $100 \mathrm{~K}$ to $300 \mathrm{~K}$. The Gibbs free energy were calculated using the parameter and these values indicated that the compound chemically strong and active.

The docking analysis shows the PHE 81 form H-bond with cyno group existence of the protein-ligand interact with the bond length of $3.0 \AA$ and PRO 90 form $\mathrm{H}$-Bond with $\mathrm{C}=\mathrm{O}$ existence of the protein-ligand interact with the bond length of $3.1 \AA$.

\section{TABLES:}

Table.1

Optimized Geometrical parameter 3-Cyano chromone Computed at B3LPY/cc-pVDZ

\begin{tabular}{|c|c|c|c|c|c|}
\hline \multicolumn{2}{|c|}{$\begin{array}{c}\text { Bond } \\
\text { Length }(\AA)\end{array}$} & XRD & \multicolumn{2}{|c|}{$\begin{array}{c}\text { Bond } \\
\left.\text { Angle ( }{ }^{\circ}\right)\end{array}$} & XRD \\
\hline \multicolumn{3}{|c|}{ Chromone ring (CC) } & \multicolumn{3}{|c|}{ Chromone ring (CCC) } \\
\hline $\mathrm{C} 1-\mathrm{C}$ & 1.39 & 1.38 & $\mathrm{C} 1-\mathrm{C} 2$ & 118. & 118. \\
\hline 2 & 1 & 9 & $-\mathrm{C} 3$ & 5 & 6 \\
\hline $\mathrm{C} 2-\mathrm{C}$ & 1.39 & 1.39 & $\mathrm{C} 2-\mathrm{C} 3$ & 122. & 122. \\
\hline 3 & 7 & 5 & $-\mathrm{C} 4$ & 1 & 0 \\
\hline C 3 - & 1.40 & 1.39 & $\mathrm{C} 3-\mathrm{C} 4$ & 118. & 117. \\
\hline
\end{tabular}

\begin{tabular}{|c|c|c|c|c|c|}
\hline $\mathrm{C} 4$ & 2 & 9 & $-\mathrm{C} 5$ & 2 & 7 \\
\hline $\mathrm{C} 4-$ & 1.40 & 1.40 & $\mathrm{C}-4-\mathrm{C} 5$ & 120. & 121. \\
\hline C5 & 8 & 6 & $-\mathrm{C} 6$ & 4 & 3 \\
\hline C $5-\mathrm{C}$ & 1.40 & 1.37 & $\mathrm{C} 2-\mathrm{C} 1$ & 120. & 120. \\
\hline 6 & 8 & 8 & $-\mathrm{C} 6$ & 6 & 6 \\
\hline $\mathrm{C} 1-\mathrm{C}$ & 1.40 & 1.40 & C $3-\mathrm{C} 4$ & 120. & 120. \\
\hline 6 & 7 & 6 & $-\mathrm{C} 9$ & 6 & 4 \\
\hline $\mathrm{C} 4-$ & 1.48 & 1.47 & C $5-\mathrm{C} 4$ & 121. & 121. \\
\hline $\mathrm{C} 9$ & 2 & 7 & $-\mathrm{C}-9$ & 1 & 8 \\
\hline $\mathrm{C} 9-\mathrm{C}$ & 1.48 & 1.46 & C $1-$ C 6 & 120. & 119. \\
\hline 12 & 1 & 4 & $-\mathrm{C} 5$ & 1 & 5 \\
\hline C 12 - & 1.36 & 1.31 & $\mathrm{C} 4-\mathrm{C} 9$ & 113. & 113. \\
\hline C 13 & 2 & 2 & $-\mathrm{C} 12$ & 2 & 4 \\
\hline \multirow{2}{*}{\multicolumn{3}{|c|}{ Cyano (CC \& CN) }} & C $9-\mathrm{C}$ & 120. & 121. \\
\hline & & & $12-\mathrm{C} 13$ & 7 & 2 \\
\hline C $12-$ & 1.43 & 1.43 & C $9-\mathrm{C}$ & 120. & 121. \\
\hline C 17 & 1 & 6 & $12-\mathrm{C} 17$ & 1 & 1 \\
\hline C 17 - & 1.16 & 1.15 & C 13 - & 119. & - \\
\hline N 18 & 2 & 3 & C12- C17 & 1 & \\
\hline \multicolumn{3}{|c|}{ Ring $(\mathrm{CO})$} & \multicolumn{3}{|c|}{ Ring (CCO) } \\
\hline C $9-\mathrm{O}$ & 1.22 & 1.22 & $\mathrm{C} 4-\mathrm{C} 9$ & 123. & 123. \\
\hline 15 & 2 & 5 & $-\mathrm{O} 15$ & 4 & 2 \\
\hline C 13 - & 1.33 & 1.35 & C $12-\mathrm{C}$ & 123. & 123. \\
\hline O16 & 9 & 4 & $9-015$ & 2 & 2 \\
\hline C $3-\mathrm{O}$ & 1.38 & 1.37 & C $2-\mathrm{C} 3$ & 116. & 116. \\
\hline 16 & 2 & 1 & $-\mathrm{O} 16$ & 3 & 1 \\
\hline \multicolumn{3}{|c|}{ Ring $(\mathrm{CH})$} & $\begin{array}{l}\text { C } 4-C 3 \\
-016\end{array}$ & $\begin{array}{r}121 . \\
6\end{array}$ & $\begin{array}{r}116 . \\
1\end{array}$ \\
\hline $\begin{array}{l}\mathrm{C} 2-\mathrm{H} \\
8\end{array}$ & $\begin{array}{r}1.08 \\
8\end{array}$ & $\begin{array}{l}1.08 \\
4\end{array}$ & \multicolumn{3}{|c|}{ Ring (CCH) } \\
\hline $\mathrm{C} 5-\mathrm{H}$ & 1.08 & 1.08 & C $1-$ C 6 & 119. & 118. \\
\hline 10 & 8 & 3 & - H 11 & 8 & 7 \\
\hline $\mathrm{C} 6-\mathrm{H}$ & 1.08 & 1.08 & C $5-\mathrm{C} 6$ & 120. & 121. \\
\hline 11 & 9 & 2 & - H 11 & 1 & 6 \\
\hline $\mathrm{C}$ & 1.08 & 1.08 & C $4-\mathrm{C} 5$ & 117. & 117. \\
\hline $\begin{array}{l}13-\mathrm{H} 1 \\
4\end{array}$ & 8 & 2 & - H 10 & 7 & 5 \\
\hline $\mathrm{C} 1-\mathrm{H}$ & 1.09 & 1.08 & C $3-$ C 2 & 119. & 119. \\
\hline 7 & 1 & 2 & $-\mathrm{H} 8$ & 5 & 4 \\
\hline & & & C $6-C 5$ & 121. & 121. \\
\hline & & & - H 10 & 7 & 0 \\
\hline & & & $\begin{array}{l}\text { C } 6-\text { C } 1 \\
-H 7\end{array}$ & 119. & 119. \\
\hline & & & C $1-\mathrm{C} 2$ & 121. & 121. \\
\hline & & & $-\mathrm{H} 8$ & 9 & 9 \\
\hline & & & $\begin{array}{l}\text { C } 2-\text { C } 1 \\
-\mathrm{H} 7\end{array}$ & $\begin{array}{r}119 . \\
4\end{array}$ & $\begin{array}{r}121 . \\
0\end{array}$ \\
\hline
\end{tabular}

Table.2

Charges of 3-Cyano chromone with B3LYP/cc-pVDZ basis set.

\begin{tabular}{|l|l|l|}
\hline \multirow{3}{*}{ Atoms } & \multicolumn{2}{|c|}{ B3LYP/cc-pVDZ } \\
\cline { 2 - 3 } & $\begin{array}{l}\text { Mullikan } \\
\text { Charge }\end{array}$ & $\begin{array}{l}\text { Natural } \\
\text { Charge }\end{array}$ \\
\hline
\end{tabular}


International Journal of Research in Advent Technology, Vol.7, No.5, May 2019 E-ISSN: 2321-9637

Available online at www.ijrat.org

\begin{tabular}{|l|r|r|}
\hline \multicolumn{3}{|c|}{ Benzene ring } \\
\hline $1 \mathrm{C}$ & 0.4682 & -0.1901 \\
\hline $2 \mathrm{C}$ & 0.8228 & -0.2527 \\
\hline $3 \mathrm{C}$ & -0.3239 & 0.3343 \\
\hline $4 \mathrm{C}$ & 2.9104 & -0.1871 \\
\hline $5 \mathrm{C}$ & 0.1830 & -0.1617 \\
\hline $6 \mathrm{C}$ & 0.3514 & -0.2255 \\
\hline $7 \mathrm{H}$ & -0.7475 & 0.2402 \\
\hline $8 \mathrm{H}$ & -0.9523 & 0.2506 \\
\hline $10 \mathrm{H}$ & -0.9863 & 0.2617 \\
\hline $11 \mathrm{H}$ & -0.7452 & 0.2409 \\
\hline & -0.0464 & 0.5402 \\
\hline $9 \mathrm{C}$ & 1.4948 & -0.3196 \\
\hline $12 \mathrm{C}$ & 0.5584 & 0.2813 \\
\hline $13 \mathrm{C}$ & -0.8396 & 0.2348 \\
\hline $14 \mathrm{H}$ & -0.6290 & -0.5692 \\
\hline $15 \mathrm{O}$ & -0.5040 & -0.4752 \\
\hline $16 \mathrm{O}$ & -0.8191 & 0.3018 \\
\hline $17 \mathrm{C}$ & -0.1953 & -0.3049 \\
\hline $18 \mathrm{~N}$ & &
\end{tabular}

Table.3

Calculated ${ }^{1} \mathrm{H}$ and ${ }^{13} \mathrm{C}$ NMR Chemical shifts (ppm) of 3-Cyano chromone

\begin{tabular}{|l|l|l|l|}
\hline \multicolumn{1}{|c|}{ Atom } & \multicolumn{4}{|c|}{ Gas } & \multicolumn{1}{|c|}{$\mathbf{C d C l}_{3}$} & Exp. \\
\hline \multicolumn{4}{|c|}{ Benzene ring } \\
\hline 1C & 123.5 & 125.4 & 123.4 \\
\hline 2C & 107.1 & 108.1 & 102.9 \\
\hline $3 \mathrm{C}$ & 147.3 & 147.7 & 155.8 \\
\hline 4C & 117.9 & 117.1 & 118.5 \\
\hline 5C & 118.7 & 117.7 & 118.5 \\
\hline 6C & 116.1 & 117 & 112.3 \\
\hline \multicolumn{5}{|c|}{ Pyrone ring } \\
\hline 9C & 163.1 & 164.8 & 162.4 \\
\hline $12 \mathrm{C}$ & 96.01 & 93.62 & 123.4 \\
\hline $13 \mathrm{C}$ & 152.1 & 155.6 & 135.4 \\
\hline $17 \mathrm{C}$ & 101.4 & 104.4 & 102.9 \\
\hline \multicolumn{5}{|c|}{ Benzene ring } \\
\hline $7 \mathrm{H}$ & 8.159 & 8.385 & 8.273 \\
\hline $8 \mathrm{H}$ & 7.953 & 8.157 & 7.805 \\
\hline $10 \mathrm{H}$ & 9.029 & 8.991 & - \\
\hline $11 \mathrm{H}$ & 8.072 & 8.239 & 7.822 \\
\hline \multicolumn{5}{|c|}{ Pyrone ring } \\
\hline $14 \mathrm{H}$ & 8.773 & 9.044 & 8.435 \\
\hline
\end{tabular}

Table.4

Vibrational Assignment

\begin{tabular}{|c|c|c|c|}
\hline \multicolumn{2}{|c|}{$\begin{array}{c}\text { Experimental } \\
\text { frequency } \\
\text { cm- }^{1}\end{array}$} & \multicolumn{2}{|c|}{ Assignment } \\
\hline $\begin{array}{l}\text { FT-I } \\
\text { R }\end{array}$ & FT-Raman & Scaled & Band \\
\hline 3263 & & 3183 & $v \mathrm{CH}$ \\
\hline & 3219 & 3171 & $v \mathrm{CH}$ \\
\hline & 3200 & 3168 & $v \mathrm{CH}$ \\
\hline & 3188 & 3157 & $v \mathrm{CH}$ \\
\hline 3173 & & 3144 & $v \mathrm{CH}$ \\
\hline 2240 & 2235 & 2300 & $v \mathrm{CN}$ \\
\hline & 1751 & 1703 & $v \mathrm{C}=\mathrm{O}$ \\
\hline 1663 & & 1635 & $v \mathrm{C}=\mathrm{C}$ \\
\hline 1616 & & 1624 & $v \mathrm{C}=\mathrm{C}$ \\
\hline 1568 & & 1586 & $v \mathrm{C}=\mathrm{C}$ \\
\hline & 1497 & 1473 & $v \mathrm{C}-\mathrm{C}$ \\
\hline 1460 & & 1463 & $v \mathrm{C}-\mathrm{C}$ \\
\hline & 1411 & 1370 & $v \mathrm{C}-\mathrm{C}$ \\
\hline 1383 & 1376 & 1360 & $v \mathrm{C}-\mathrm{C}$ \\
\hline 1346 & & 1317 & $v \mathrm{C}-\mathrm{C}$ \\
\hline 1271 & & 1263 & $v \mathrm{C}-\mathrm{C}$ \\
\hline 1222 & & 1222 & $v \mathrm{C}-\mathrm{C}$ \\
\hline & 1190 & 1178 & $v \mathrm{CO}$ \\
\hline 1178 & & 1169 & $v \mathrm{CO}$ \\
\hline 1147 & & 1145 & $\beta \mathrm{CH}$ \\
\hline & 1126 & 1099 & $\beta \mathrm{CH}$ \\
\hline 1024 & & 1032 & $\beta \mathrm{CH}$ \\
\hline & 1015 & 1004 & $\beta \mathrm{CH}$ \\
\hline 981 & & 973 & $\beta \mathrm{CH}$ \\
\hline 939 & & 927 & $\beta \mathrm{C}=\mathrm{O}$ \\
\hline & 928 & 920 & $\beta \mathrm{CC}$ \\
\hline & 888 & 884 & $\gamma \mathrm{CH}$ \\
\hline 848 & & 841 & $\gamma \mathrm{CH}$ \\
\hline & 820 & 813 & $\gamma \mathrm{CH}$ \\
\hline 764 & & 766 & $\gamma \mathrm{CH}$ \\
\hline & 735 & 743 & $\gamma \mathrm{CH}$ \\
\hline 694 & & 711 & $\gamma \mathrm{CC}$ \\
\hline 665 & & 665 & $\gamma \mathrm{C}=\mathrm{O}$ \\
\hline 625 & & 625 & $\beta \mathrm{CN}$ \\
\hline & 560 & 549 & $\tau \mathrm{CCO}$ \\
\hline 537 & & 537 & $\tau \mathrm{CCO}$ \\
\hline & 511 & 527 & $\varphi \mathrm{CN}$ \\
\hline & 501 & 484 & $\tau \mathrm{CCO}$ \\
\hline 451 & & 455 & $\tau \mathrm{CCO}$ \\
\hline 430 & 423 & 427 & $\tau \mathrm{CCN}$ \\
\hline 404 & 410 & 408 & $\tau \mathrm{CCH}$ \\
\hline & 388 & 374 & $\tau \mathrm{CCH}$ \\
\hline
\end{tabular}




\begin{tabular}{|c|c|c|c|}
\hline & 188 & 287 & $\tau \mathrm{CCH}$ \\
\hline- & - & 242 & $\tau \mathrm{CCC}$ \\
\hline- & - & 214 & $\tau \mathrm{CCC}$ \\
\hline- & - & 132 & $\tau \mathrm{CCC}$ \\
\hline- & - & 130 & $\tau \mathrm{CCC}$ \\
\hline- & - & 62 & $\tau \mathrm{CCC}$ \\
\hline
\end{tabular}

$\nu$-stretching; $\beta$-in-plane bending; $\gamma$-out of plane bending; and $\tau$-torsion.

\section{Table.5}

Second order perturbation theory of Fock matrix in NBO basis of 3-Cyano chromone

\begin{tabular}{|c|c|c|c|c|c|c|}
\hline Donor & $\begin{array}{l}\mathrm{T} \\
\mathrm{y} \\
\mathrm{p} \\
\mathrm{e}\end{array}$ & $\begin{array}{l}\text { Occu } \\
\text { pancy }\end{array}$ & $\begin{array}{l}\text { Accepto } \\
\text { r }\end{array}$ & $\begin{array}{l}\text { Ty } \\
\text { pe }\end{array}$ & $\begin{array}{l}\text { Occu } \\
\text { pancy }\end{array}$ & $\mathrm{E}(2)$ \\
\hline O 16 & $\mathrm{n}$ & 1.72 & $\begin{array}{l}\text { C12 } \\
-C 13\end{array}$ & $\pi^{*}$ & 0.21 & 35.7 \\
\hline O 16 & $\mathrm{n}$ & 1.72 & $\mathrm{C} 3-\mathrm{C} 4$ & $\pi^{*}$ & 0.41 & 25.2 \\
\hline C 1-C2 & $\pi$ & 1.68 & $\mathrm{C} 3-\mathrm{C} 4$ & $\pi^{*}$ & 0.41 & 22.2 \\
\hline O 15 & $\mathrm{n}$ & 1.88 & C9-12 & $\pi^{*}$ & 0.07 & 21.9 \\
\hline C 5-C6 & $\pi$ & 1.67 & $\mathrm{C} 1-\mathrm{C} 2$ & $\pi^{*}$ & 0.29 & 21.6 \\
\hline $\begin{array}{l}\mathrm{C} 12-\mathrm{C} \\
3\end{array}$ & $\pi$ & 1.81 & $\begin{array}{l}\text { C } \\
9-015\end{array}$ & $\pi^{*}$ & 0.23 & 21.3 \\
\hline C3-C 4 & $\pi$ & 1.63 & $\begin{array}{l}\text { C9-O1 } \\
5 \\
\end{array}$ & $\pi^{*}$ & 0.23 & 20.5 \\
\hline O 15 & $\mathrm{n}$ & 1.88 & C4-C9 & $\pi^{*}$ & 0.06 & 19.8 \\
\hline C5-C 6 & $\pi$ & 1.67 & C3-C4 & $\pi^{*}$ & 0.41 & 18.8 \\
\hline C3-C4 & $\pi$ & 1.63 & C5-C6 & $\pi^{*}$ & 0.26 & 18.0 \\
\hline $\begin{array}{l}\mathrm{C} 12-\mathrm{C} \\
13\end{array}$ & $\pi$ & 1.81 & $\begin{array}{l}\text { C17 - } \\
\text { N18 }\end{array}$ & $\pi^{*}$ & 0.07 & 17.7 \\
\hline C3-C 4 & $\pi$ & 1.63 & $\mathrm{C} 1-\mathrm{C} 2$ & $\pi^{*}$ & 0.29 & 16.4 \\
\hline $\mathrm{C} 1-\mathrm{C} 2$ & $\pi$ & 1.68 & C5-C6 & $\pi^{*}$ & 0.26 & 16.2 \\
\hline N 18 & $\mathrm{n}$ & 1.97 & $\begin{array}{l}\text { C12- } \\
\text { C17 }\end{array}$ & $\begin{array}{l}\pi \\
*\end{array}$ & 0.02 & 12.4 \\
\hline
\end{tabular}

Table: 6

Theoretical electronic absorption spectra of 3-Cyano chromone (absorption wavelength $\lambda(\mathrm{nm})$, excitation energies $\mathrm{E}(\mathrm{eV})$ and oscillator strengths (f) using TD-DFT/B3LYP/6-311++G(d,p) method.

\begin{tabular}{|c|c|c|c|c|}
\hline \multicolumn{2}{|c|}{$\lambda(\mathrm{nm})$} & \multirow{3}{*}{$\mathrm{E}(\mathrm{eV})$} & \multirow{3}{*}{ (f) } & \multirow{3}{*}{ Major contribution } \\
\hline $\mathrm{T}$ & $\mathrm{E}$ & & & \\
\hline \multicolumn{2}{|c|}{ Gas } & & & \\
\hline 340 & & 3.642 & 0.0002 & H-1->LUMO (96\%) \\
\hline 293 & & 4.231 & 0.2340 & $\begin{array}{l}\text { HOMO->LUMO } \\
(88 \%)\end{array}$ \\
\hline
\end{tabular}

\begin{tabular}{|l|l|l|l|l|}
\hline 282 & & 4.384 & 0.0725 & H-1->L+1 $(98 \%)$ \\
\hline 254 & & 4.873 & 0.0019 & H-2->LUMO (33\%) \\
\hline 252 & & 4.905 & 0.0052 & H-2->LUMO (53\%) \\
\hline 239 & & 5.180 & 0.0226 & H-3->LUMO (82\%) \\
\hline 236 & & 5.239 & 0.1153 & H-3->L+1 $(28 \%)$ \\
\hline 232 & & 5.341 & 0.0043 & H-1->L+2 $(98 \%)$ \\
\hline 228 & & 5.425 & 0.0006 & H-3->L+1 $(23 \%)$ \\
\hline 226 & & 5.472 & 0.0021 & H-4->LUMO (82\%) \\
\hline Ethanol & & & \\
\hline 309 & & 4.000 & 0.0000 & H-1->LUMO (95\%) \\
\hline 289 & 270 & 4.277 & 0.3116 & HOMO->LUMO \\
& & & & $(91 \%)$ \\
\hline 268 & & 4.612 & 0.0076 & H-2->LUMO (43\%) \\
\hline 254 & & 4.864 & 0.0860 & H-2->LUMO (48\%) \\
\hline 254 & & 4.876 & 0.0000 & H-1->L+1 (97\%) \\
\hline 234 & & 5.276 & 0.1548 & H-3->LUMO (82\%) \\
\hline 228 & & 5.430 & 0.1867 & H-3->L+1 $(16 \%)$ \\
\hline 215 & & 5.751 & 0.0342 & H-3->L+1 (50\%) \\
\hline 205 & & 6.032 & 0.0001 & H-1->L+2 (98\%) \\
\hline 202 & & 6.110 & 0.0926 & H-3->L+1 (11\%) \\
\hline
\end{tabular}

Table.7

Homo - Lumo of3-Cyano chromone.

\begin{tabular}{|l|c|}
\hline Parameters & Gas \\
\hline $\mathrm{E}_{\mathrm{HOMO}}(\mathrm{eV})$ & -0.27342 \\
\hline $\mathrm{E}_{\mathrm{LUMO}}(\mathrm{eV})$ & -0.0247 \\
\hline$\Delta \mathrm{E}_{\text {HOMO-LUMO gap }}(\mathrm{eV})$ & -0.2095 \\
\hline Electronegativity $(\chi)(\mathrm{eV})$ & 0.14906 \\
\hline Global hardness $(\eta)(\mathrm{eV})$ & 0.12436 \\
\hline Global softness $(\mathrm{S})(\mathrm{eV})$ & 0.49744 \\
\hline Electrophilicity index $(\omega)(\mathrm{eV})$ & 0.08925 \\
\hline Dipole Moment $(\mu)($ debye $)$ & 4.9769 \\
\hline
\end{tabular}

Table 8:

NLO Properties of 3-Cyanmo chromone

\begin{tabular}{|c|c|c|c|}
\hline $\begin{array}{c}\text { Para } \\
\text { mete }\end{array}$ & a.u. & $\begin{array}{c}\text { Para } \\
\text { meter }\end{array}$ & a.u. \\
\hline$\alpha_{\mathrm{xx}}$ & -85.6907 & $\beta_{\mathrm{xxx}}$ & 157.0949 \\
\hline$\alpha_{\mathrm{xy}}$ & 8.3911 & $\beta_{\mathrm{xyy}}$ & 12.6748 \\
\hline$\alpha_{\mathrm{yy}}$ & -72.3790 & $\beta_{\mathrm{xzz}}$ & -6.9069 \\
\hline$\alpha_{\mathrm{xz}}$ & 0.0000 & $\beta_{\mathrm{yyy}}$ & -21.0180 \\
\hline$\alpha_{\mathrm{zz}}$ & -74.9141 & $\beta_{\mathrm{yxx}}$ & -16.9895 \\
\hline$\alpha_{\mathrm{yz}}$ & -0.0003 & $\beta_{\mathrm{yzz}}$ & -0.4301 \\
\hline$\alpha_{\mathrm{tot}}$ & $-77.6589^{*}$ & $\beta_{\mathrm{zzz}}$ & -0.0008 \\
& $10^{24} \mathrm{esu}$ & & \\
\hline$\Delta \alpha$ & $190.908^{*}$ & $\beta_{\mathrm{zyy}}$ & 0.0012 \\
& $10^{24} \mathrm{esu}$ & & \\
& & & \\
\hline
\end{tabular}




\begin{tabular}{|c|c|c|c|}
\hline$\mu_{\mathrm{x}}$ & 6.6090 & $\beta_{\mathrm{zxx}}$ & 0.0022 \\
\hline$\mu_{\mathrm{y}}$ & -3.6704 & $\beta_{\mathrm{xyz}}$ & 0.0001 \\
\hline$\mu_{\mathrm{z}}$ & 0.0003 & $\beta_{\text {tot }}$ & $\begin{array}{c}167.24^{*} 10^{-33} \\
\text { esu }\end{array}$ \\
\hline$\mu_{\text {tot }}$ & 7.5599 & & \\
\hline
\end{tabular}

Table 9:

Thermodynamic properties at different temperatures of 3-Cyano chromone

\begin{tabular}{|c|c|c|c|}
\hline $\mathrm{T}(\mathrm{K})$ & $\begin{array}{c}\mathrm{C}_{\mathrm{m}}^{\circ} \\
\text { (cal mol }^{-1} \\
\left.\mathrm{~K}^{-1}\right)\end{array}$ & $\begin{array}{c}\mathrm{S}_{\mathrm{m}}^{\circ} \\
\text { (cal mol }^{-1} \\
\left.\mathrm{~K}^{-1}\right)\end{array}$ & $\begin{array}{c}\Delta \mathrm{H}_{\mathrm{m}}^{\circ} \\
\left(\mathrm{cal} \mathrm{mol}^{-1}\right. \\
\left.\mathrm{K}^{-1}\right)\end{array}$ \\
\hline 100 & 13.983 & 68.576 & 79.877 \\
\hline 200 & 25.430 & 83.062 & 81.834 \\
\hline 300 & 37.314 & 96.446 & 84.975 \\
\hline
\end{tabular}

$\mathbf{C}_{\mathrm{m}}$ - Heat capacity; $\mathrm{S}_{\mathrm{m}}$-Entropy; $\Delta \mathrm{H}_{\mathrm{m}-\text { Enthalpy }}$

Table .10

Molecular docking analysis of 3-Cyano chromone

\begin{tabular}{|c|c|c|c|c|}
\hline $\begin{array}{c}\text { Protei } \\
\text { n (PDB } \\
\text { ID) }\end{array}$ & $\begin{array}{c}\text { Binding } \\
\text { energy } \\
\text { (kcal/mo } \\
\text { I) }\end{array}$ & $\begin{array}{c}\text { No. of } \\
\text { hydroge } \\
\text { n bonds }\end{array}$ & $\begin{array}{c}\text { Bonded } \\
\text { Residue } \\
\text { s }\end{array}$ & $\begin{array}{c}\text { Bond } \\
\text { Distanc } \\
\text { e }\end{array}$ \\
\hline 3U3M & 5.52 & 2 & PHE 81 & 3.0 \\
\cline { 4 - 5 } & & & PRO 90 & 3.1 \\
\hline
\end{tabular}

ACKNOWLEDGMENTS

We remain grateful to Kanchi Mamunivar

Center for Post Graduates studies, Lawspet, Puducherry for providing the Quantum Computational Research Lab for this study. (A.1)

\section{REFERENCES}

[1] Robert Vianelloa, Zvonimir B. Maksica, Tetrahedron 61 (2005) 9381.

[2] W.D. Watson, in: B.H. Andrew, D. Reidel (Eds.), Interstellar Molecules, Kluwer, Dordrecht, p. 1980.

[3] J. Benkhoff, Adv. Space Res. 29 (2002) 11771186.

[4] J.P. Ferris, in: S. Patai, Z. Rappaport (Eds.), The Chemistry of Functional Groups,Supplement C, Wiley, Chichester, New York, 1983, p. 325.
[5] Hamdy R. Soltan, Alex. J. Pharm. Sci. 15 (2001) 137.

[6] Haifeng Song, Kongchang Chen, He. Tian, Dye Pig. 53 (2002) 257.

[7] Fang Yao, Bin Huang, MingzhongCai, J. Chem. Res. 6 (2009) 366.

[8] William H. Daly, Munir Arshad, J. Polym. Sci., Polym. Chem. Ed. 22 (1984)975.

[9] TomizawaMotohiro, Todd T. Talley, David Maltby, Kathleen A. Durkin, KatalinF. Medzihradszky, Alma L. Burlingame, Palmer Taylor, John E. Casida, Proc.Natl. Acad. Sci. USA 104 (2007) 9075.

[10] S. Cheylan, A. Fraleoni-Morgera, J. Puigdollers, C. Voz, L. Setti, R. Alcubilla, G.Badenes, P. Costa-Bizzarri, M. Lanzi, Thin Solid Films 497 (2006) 16.

[11]N. Saemian, G. Shirvani, H. Matloubi, J. Radioanal. Nucl. Chem. 268 (2006)545.

[12] R. Dennington, T. Keith. J. Millam, Gauss view, Semichem Inc., shawnee mission, K. S, 2009, version 9.

[13] K. Jayasheela, S. Periandy, S. Xavier, K. Niveditha,Docking and spectral investigations (FT-IR, FT-Raman, NMR, UV-Vis) ON 7-Hydroxyl-4-Chromone using quantumComputational (DFT) analysis, [https://doi.org/10.15623/ijret.2018.0702008]

[14] J. J. Nie, D. J. Xu, Chin. Struct, J. Chem.,21 (2002) 165.

[15]S. Manohar, R. Nagalakshmi and V. Krishnakumar, SpectrochemicaActa Part A 71 (2008) 110

[16] G. Mariappan, N. Sundaraganesan, J. Mol. Struct., 1063 (2014) 192.

[17] J.T. Hoeft Surface Science 540 (2003) 441-456

[18]R.S. Mulliken, J. Chem. Phys. 23 (1955) 18331840

[19] S.K. Wolff, D.J. Grimwood, J.J. Mckinnon, M.J. Turner, D. Jayailaka, M.A. Spackman, University Western, Australia, 2012

[20] S. Chandra, SpectrochimicaActa Part A 74 (2009) 704-713

[21]E. K. Sarıkaya, S. Bahçeli, D. Varkal, O. Dereli, Journal of Molecular Structure 1141(2017) 44-52

[22] V. Karunakaran, V. Balachandran, Spectrochim. Acta A (2014) 1-14

[23] J.M.Chalmers and P.R.Griffith, Raman Spectroscopy:Theory in Handbook of Vibrational Spectroscopy, Vol. 1 John Wiley \& Sons Ltd., New York, ( 2002) 71-73.

[24] N.E.H. Belkafouf, F.T. Baara, A. Altomare, R. Rizzi, A. Chouaih, A. Djafri, F. Hamzaoui, Journal of Molecular Structure (2019)

[25] N. Sundaraganesan, H. Saleem, S. Mohan, M. Ramalingam, V. Sethuraman,Spectrochim. Acta A 62 (2005) 740e 751. 
[26] G. Socrates, Infrared and Raman Characteristic Group Frequencies-Table and charts, third edition, Wiley, New York, 2001

[27] J. Arthur, L. Plante, D.H. Stidham, Spectrochim, Acta A 74 (2009) 808-818.

[28] R.N. Singh, A. Kumar, R.K. Tiwari, P. Rawat, Spectrochim. Acta A 113 (2013)378-385

[29] R. Gayathri, M. Arivazhagan, Spectrochim. Acta 97 (2012) 311e325.

[30] N. Udaya Sri et al., Molecular and Biomolecular Spectroscopy, SpectrochimActa Part A 97 (2012) 728-736.

[31] T. Gnanasambandan, S. Gunasekaran, S. Seshadri, Spectrochim. Acta 122(2014) 542e552.

[32] F. Weinhold, C.R. Landis, Chem. Educ. Res. Pract. 2 (2001) 91.

[33] A. Smith, Infrared Spectral Interpretation: A Systematic Approach, CRC Press, Washington, DC, 1999

[34] K.V. Raman, et al., Molecular Spectroscopy, Vijay Nicole Imprints Private Limited, 2004.

[35] S.I. Gorelsky, SWizard Program Revision 4.5, University of Ottawa, Ottawa, Canada, 2010.

[36] Journals of computer science and net workingMekhala. R et al., (2015) Theoretical science 2:127 doi[10.4172/2376130X.1000127].

[37] G. Socrates, Infrared and Raman Characteristic Frequencies, 3rd ed., John Wiley\& Sons Ltd., Chichester, 2001.

[38] V.R. Dani, Organic Spectroscopy, Tata-Mac Graw Hill Publishing Company, New Delhi, 1995, p. 139.

[39] T. Koopmans, Physica 1 (1934) 104-113.

[40] R.S. Mulliken, J. Chem. Phys. 2 (1934) 782-793.

[41] R.G. Pearson. J. Am. Chem. Soc. 107(1985) 6801-6906.

[42] W. Yang, P.G. Parr, Porc. Natl. Acad. Sci. U.S.A. 82 (1985) 6723-6726.

[43] P.G. Parr, W. Yang, Density Functional Theory Of Atoms And Molecules, Oxford University Press, New York, 1989.

[44]D.A. Kleinmann, Phys. Rev. 126 (1962) $1977-$ 1979.

[45] E.R. Johndon, S. Keinan, P. Mori-sanchez, J. Conctreas-Garcia, A.J. Cohen, W. Yang, Revvealing non covalent interactions, J. Am. /Chem. Soc. 132 (18) (2010) 6498-6506.

[46] W. Humphrey, A. Dalke, K.Schuten, VMD: Visual molecular dynamics. J. Mol.Graph 14(1) (1996) 33-38.

[47]R.F. Bader. A quatum theory of molecular structure and its applications chem. Rev 91 (5) (1991)893-928.

[48] Berger, I., Guttman, C., Amar, D., Zarivach, $\underline{\text { R., Aharoni, A. Protein data bank (2011) Plos }}$ One 6: e26794-e26794. 10.1371/journal.pone.0026794

[49] K.Jayasheela, lamya H. Al-wahaibi, S.Periandy, Hanan M. Hassan, S.Sebastian, Xavier, Joseph
C.Daniel, Ali A. El-Emam, Mohamed I. Attia Journal of molecular structure 1159 (2018) 83-95 